NBER WORKING PAPER SERIES

\title{
PRICE VERSUS QUANTITY: MARKET \\ CLEARING MECHANISMS WHEN \\ SELLERS DIFFER IN QUALITY
}

\author{
Andrew Metrick \\ Richard Zeckhauser
}

Working Paper 5728

\section{NATIONAL BUREAU OF ECONOMIC RESEARCH 1050 Massachusetts Avenue \\ Cambridge, MA 02138 \\ August 1996}

We thank Miriam Avins, Malcolm Brachman, Ed Glaeser, Marc Jacobus, Eddie Wold, and participants in the Harvard Industrial Organization Seminar for helpful comments. Roy Astrachan, Brian Gordon, and Darlene Lin provided excellent research assistance. Comments are appreciated. This paper is part of NBER's research program in Industrial Organization. Any opinions expressed are those of the authors and not those of the National Bureau of Economic Research.

(C) 1996 by Andrew Metrick and Richard Zeckhauser. All rights reserved. Short sections of text, not to exceed two paragraphs, may be quoted without explicit permission provided that full credit, including $(\odot$ notice, is given to the source. 


\title{
PRICE VERSUS QUANTITY: MARKET \\ CLEARING MECHANISMS WHEN \\ SELLERS DIFFER IN QUALITY
}

\begin{abstract}
High-quality producers in a vertically differentiated market can reap superior profits by charging higher prices, selling greater quantities, or both. If qualities are known by consumers and production costs are constant, then having a higher quality secures the producer both higher price and higher quantity; if marginal costs are rising, having a higher quality assures only higher price. If only some consumers can discern quality but others cannot, then high- and low-quality producers may set a common price, but the high-quality producer will sell more. In this context, quality begets quantity. Empirical analyses suggest that in both the mutual fund and automobile industries, highquality producers sell more units than their low-quality competitors, but at no higher price (or markup) per unit.
\end{abstract}

Andrew Metrick

Department of Economics

Harvard University

Cambridge, MA 02138
Richard Zeckhauser

Kennedy School of Government

Harvard University

Cambridge, MA 02138 and NBER

richardz@ksg1.harvard.edu 


\section{Introduction}

You need an electrician. If you are fortunate, you are a well-informed consumer and you know who is good, and who is not. A less-informed consumer, perhaps with no recourse beyond the Yellow Pages, is more likely to end up with a low-quality electrician.

Markets of this type are common. They are found with professionals such as caterers, doctors, and movers, with services such as mutual funds, airlines, and resorts, and with consumer durables such as automobiles, dishwashers and VCRs. Though quality differs significantly among providers, many consumers do not know which ones are of high quality.

In such markets, casual observation suggests, suppliers whose qualities differ may charge similar prices; that is, firms compete on quality within a tight price range. For example, numerous magazine and newspaper articles analyze the quality of similarly-priced goods such as "no-load" mutual funds and "economy" cars; if some goods are found to have higher quality by many sources, would their producers earn their superior rents by raising prices or by selling more units? In both the mutual fund and automobile industries, the latter mechanism seems to apply: the quantity sold by a firm is positively related to its product's perceived quality, while the price markup over cost has little or no relationship with quality. ${ }^{1}$ We refer to this phenomenon as "quantity clearing the market". 2

In this paper, we ask: "Under what conditions would a 'high-quality' producer choose to reap its rents through greater quantity rather than higher price?" We focus on a duopoly where the sellers differ in quality. ${ }^{3}$ Markets where products differ in characteristics that can be strictly ordered in terms of desirability are called vertically differentiated markets. We use this framework to study the role of costs and imperfect information on relative market shares, and we identify subtle and powerful mechanisms that allow different quantities sold,

\footnotetext{
1 See section 5.

2 This idea was inspired by the experience of professional bridge players, who are hired by customers to play on teams in tournaments. Casual observation suggests that prices per tournament tend to be close across quality levels, but that the top professionals tend to have jobs for a substantially greater proportion of tournaments than their lower-ranked brethren. Thus, the rents to quality are reaped primarily through the mechanism of quantity, not price.

3 Market outcomes with many sellers are discussed in the Appendix.
} 
rather than different prices, to be the primary mechanism that clears the market. ${ }^{4}$

The notion that product differentiation can soften price competition has a long and distinguished history. Chamberlain (1933) first suggested a model of product differentiation as a means to avoid Bertrand's (1883) zero-profit duopoly result and to more realistically model monopolistic competition. For almost 50 years after that, the focus was on horizontal differentiation, with "location" the best-studied example. In the late 1970s and early 1980s, several economists began to study vertically differentiated markets. The early literature on this subject focused on the properties of equilibria and tried to find general conditions under which such industries would have a limited number of firms in equilibrium. ${ }^{5}$ Researchers subsequently combined models of vertical and horizontal differentiation to study a range of topics. ${ }^{6}$ However, there has been relatively little work on the relationship between quality and market share, because even simple models can yield conflicting answers. ${ }^{7}$ In this paper, we make no claims of having resolved these conflicts; rather, we aim to identify the strategic incentives that can lead to large differences in quantities in the presence of small (or no) differences in prices.

Section 2 presents our basic model of a vertically differentiated duopoly with perfect information and no costs of production, a setup similar to that chosen by earlier authors. Section 3 extends the model to allow for convex costs. We find that the relationships among qualities and quantities found in a model without costs no longer apply when costs are included.

Section 4 presents the main result of the paper. Here, we add a class of imperfectly informed consumers to the zero-cost model of section 2 . We find that under some reasonable

4 In our paper, quantity means "actual quantity sold". Thus, we are not presenting a model of equilibrium queues and explaining why some restaurants, movies, etc. have persistent excess demand. This famous problem is outside our current scope. See Becker (1991) for a model of this phenomenon.

5 See Gabszewicz and Thisse (1979, 1980), Shaked and Sutton (1982, 1983), and Sutton (1986). Tirole (1988) provides a helpful overview of the main results on such markets.

6 For examples of this more recent work see Motta (1993), Hackner (1994), Rosenkranz (1995), and Boom (1995).

7 Sutton (1986) points out that the literature on vertical differentiation can give no general results about the relationship between quality and market share. One attempt to focus on this relationship is Gabszewicz et. al (1981), but their results are for a specific type of consumer utility function. Rosen (1981) studies the "superstar" phenomenon. Many of his insights are also applicable to our problem, although his superstars tend to supply higher quantities and charge higher prices. 
conditions, both firms would prefer to post the same price (pooling) rather than post different prices (separating). Compared to the separating equilibrium, pooling reduces both efficiency and the total number of consumers who are served; the imperfect information allows the firms to relax their price competition in a tacit but effective manner, leading to an equilibrium in which the two firms may serve significantly different numbers of consumers.

Section 5 presents two empirical studies that address the relationships among quantity, price markups, and quality in the mutual fund and automobile industries, and find results consistent with the model of section 4. Section 6 concludes. An Appendix provides detailed solutions for the models studied in sections 3 and 4 , as well as a many-firm extension of the model presented in section $2 .^{8}$

\section{A Basic Model of Vertically Differentiated Duopoly}

Our basic model assumes that there are no costs of production and that both consumers and producers have perfect information. We work in a partial equilibrium framework, focusing on a single consumption good. There are two producers of this good, indexed by $m$ : a high-quality producer, $m=\mathrm{H}$, with quality $\theta_{H}$, and a low-quality producer, $m=\mathrm{L}$, with quality $\theta_{L}$. We assume that $0<\theta_{L}<\theta_{H} \leq 1$, and we define $\alpha$ as the ratio between the qualities of $\mathrm{L}$ and $\mathrm{H}: \alpha=\frac{\theta_{L}}{\theta_{H}}$, hence $0<\alpha<1$. For semantic ease, we will use female pronouns for $\mathrm{H}$ and male pronouns for L. In equilibrium, our producers will earn profits, but entry will not occur because (by assumption) our industry is made up of producers with scarce skills, which can earn rents. For example, high-quality electricians, mutual funds, and automobile producers earn rents, and these rents will not be dissipated by entry as long as the underlying high capability cannot quickly be reproduced. When quality takes the form of an innate talent or a skill that is difficult to acquire, then this assumption is reasonable. ${ }^{9}$ Once we can safely ignore entry, our task is to model the market for different fixed numbers of producers. Duopoly is the logical first step. The Appendix sketches the solution to the model with multiple firms, and gives an illustration for a special case of a 5-firm industry.

\footnotetext{
8 Solutions for a model in which duopolists set prices simultaneously and for a model in which the lowquality seller sets price first are available from the authors.

9 Even for manufactured goods like automobiles, quality may be impossible to reproduce in the short run, and very costly to reproduce in the long run.
} 
Let a consumer's "valuation" for the consumption good be denoted by $v$. Each consumer can buy either zero or one unit of the good. There is a continuum of consumers, indexed by their valuation, $v$, on the interval $[0,1]$. The benefit to a consumer from purchasing one unit from producer $m$ is $v \theta_{m}$; the cost is the price, $P_{m}$. Thus, the specific realization of the utility function is

$$
U(\theta, v)=v \theta_{m}-P_{m}
$$

if the consumer buys one unit of the good from producer $m$, and

$$
U(\theta, v)=0
$$

otherwise. We assume that consumers always have enough money to buy one unit of the good if it is optimal to do so. We also assume that when a consumer is indifferent between buying and not buying, he buys, and when he is indifferent between buying the two types of goods, he buys from $\mathrm{H}$. The utility function used here is similar to the one chosen by earlier writers on vertical differentiation. ${ }^{10}$ If there were only one quality available, then this model of consumption would imply a linear market demand curve where the fraction of consumers willing to buy a good of quality $\theta_{m}$ at any price $P$ would be equal to $1-\frac{P}{\theta_{m}}$.

The sequence of events is

(1) $\mathrm{H}$ chooses her price, $P_{H}$.

(2) L chooses his price, $P_{L}$.

(3) Each consumer can: (A) purchase one unit from $\mathrm{H}$, (B) purchase one unit from L, or (C) make no purchase.

This sequential price-setting rule differs from the rule used in most of the previous literature on vertical differentiation, where firms generally set prices simultaneously. We have $\mathrm{H}$ set her price first because it is the simplest way to model imperfect information (which we do in section 4). For now, we still assume that consumers can costlessly determine the quality of both producers.

\footnotetext{
10 See Gabszewicz and Thisse (1979, 1980) and Shaked and Sutton $(1982,1983)$. To generate the market segmentation between different qualities, the utility functions used by these authors use differences in income rather than differences in valuations. In fact, the two approaches are isomorphic.
} 
We solve the game backwards to find the equilibrium level of prices, quantities, and purchase decisions. First, a consumer will

A) buy the high-quality good if

(1) $v \theta_{H}-P_{H} \geq v \theta_{L}-P_{L} \rightarrow v \geq \frac{P_{H}-P_{L}}{\theta_{H}-\theta_{L}}$

and

(2) $v \theta_{H}-P_{H} \geq 0 \rightarrow v \geq \frac{P_{H}}{\theta_{H}}$

B) buy the low-quality good if

(1) $v \theta_{L}-P_{L}>v \theta_{H}-P_{H} \rightarrow v<\frac{P_{H}-P_{L}}{\theta_{H}-\theta_{L}}$

and

(2) $v \theta_{L}-P_{L} \geq 0 \rightarrow v \geq \frac{P_{L}}{\theta_{L}} ;$ and

C) otherwise, a consumer will not buy.

We next turn to L's price-setting problem. L knows the distribution of consumers and their optimal conditions. Production is costless. ${ }^{11}$ The sellers maximize profit, $\pi$, which absent costs is simply price times quantity. Thus, L seeks to maximize

$$
\pi_{L}=Q_{L} P_{L}
$$

where $Q_{L}$ is L's quantity. Using conditions B.1 and B.2, we can see that the quantity for this producer will be

$$
Q_{L}=\left(\frac{P_{H}-P_{L}}{\theta_{H}-\theta_{L}}-\frac{P_{L}}{\theta_{L}}\right)
$$

Therefore, L's profit function can be written as

$$
\pi_{L}=\left(\frac{P_{H}-P_{L}}{\theta_{H}-\theta_{L}}-\frac{P_{L}}{\theta_{L}}\right) P_{L} .
$$

The first-order condition for $\mathrm{L}$ is

$$
\frac{\partial \pi_{L}}{\partial P_{L}}=0=\left(\frac{P_{H}-P_{L}}{\theta_{H}-\theta_{L}}-\frac{P_{L}}{\theta_{L}}\right)-\left(\frac{1}{\theta_{H}-\theta_{L}}+\frac{1}{\theta_{L}}\right) P_{L}
$$

\footnotetext{
11 This no-cost assumption is a normalization, and all the results of this section would be identical if we used a constant marginal-cost production function as long as the continuum of consumer valuations had some mass above the level of marginal costs.
} 
We can then solve for $P_{L}$ as

$$
P_{L}=\frac{\theta_{L} P_{H}}{2 \theta_{H}} .
$$

So L's price will always be proportional to H's price, with a proportion equal to $\frac{\theta_{L}}{2 \theta_{H}}$, one-half the ratio between the two quality levels.

Finally, we turn to H's price-setting problem. From (7) it can be verified that $\frac{P_{H}-P_{L}}{\theta_{H}-\theta_{L}}>\frac{P_{H}}{\theta_{H}}$ for all optimal choices of $P_{L}$ by $L$. Thus, for any level of $P_{L}$ that could be set in equilibrium,

$$
Q_{H}=\left(1-\frac{P_{H}-P_{L}}{\theta_{H}-\theta_{L}}\right) .
$$

Replacing $P_{L}$ by its optimal value, we can write H's profits as

$$
\pi_{H}=\left(1-\frac{P_{H}-\frac{\theta_{L} P_{H}}{2 \theta_{H}}}{\theta_{H}-\theta_{L}}\right) P_{H} .
$$

H seeks to maximize these profits with respect to $P_{H}$. Solving for the optimal $P_{H}$ yields

$$
P_{H}=\frac{\theta_{H}\left(\theta_{H}-\theta_{L}\right)}{2 \theta_{H}-\theta_{L}}
$$

Finally, we substitute (10) into (7) to obtain

$$
P_{L}=\frac{\theta_{L}\left(\theta_{H}-\theta_{L}\right)}{2\left(2 \theta_{H}-\theta_{L}\right)}
$$

Figure 1 plots $P_{H}$ and $P_{L}$ against $\theta_{L}$ for the case of $\theta_{H}=1$. At $\theta_{L}=0, \mathrm{H}$ effectively possesses a monopoly, and thus sets the monopoly price, $P_{H}=.5$. As $\theta_{L}$ rises, $\mathrm{H}$ faces increasing competition, and her optimal price falls. Two counteracting factors affect the level of $P_{L}$ as $\theta_{L}$ rises: first, increases in $\theta_{L}$ raise the ratio of equilibrium prices $\frac{P_{L}}{P_{H}}$; second, increases in $\theta_{L}$ cause $P_{H}$ to fall. As long as $P_{H}$ is high enough, the first effect dominates, and $P_{L}$ increases with $\theta_{L}$. When $P_{H}$ falls low enough so that increases in the ratio are not sufficient to offset decreases in the level of $P_{H}$, the second effect dominates, and $P_{L}$ decreases with $\theta_{L}$. 


\section{Figure 1 - Prices for $\mathrm{H}$ and L as a Function of L's Quality}

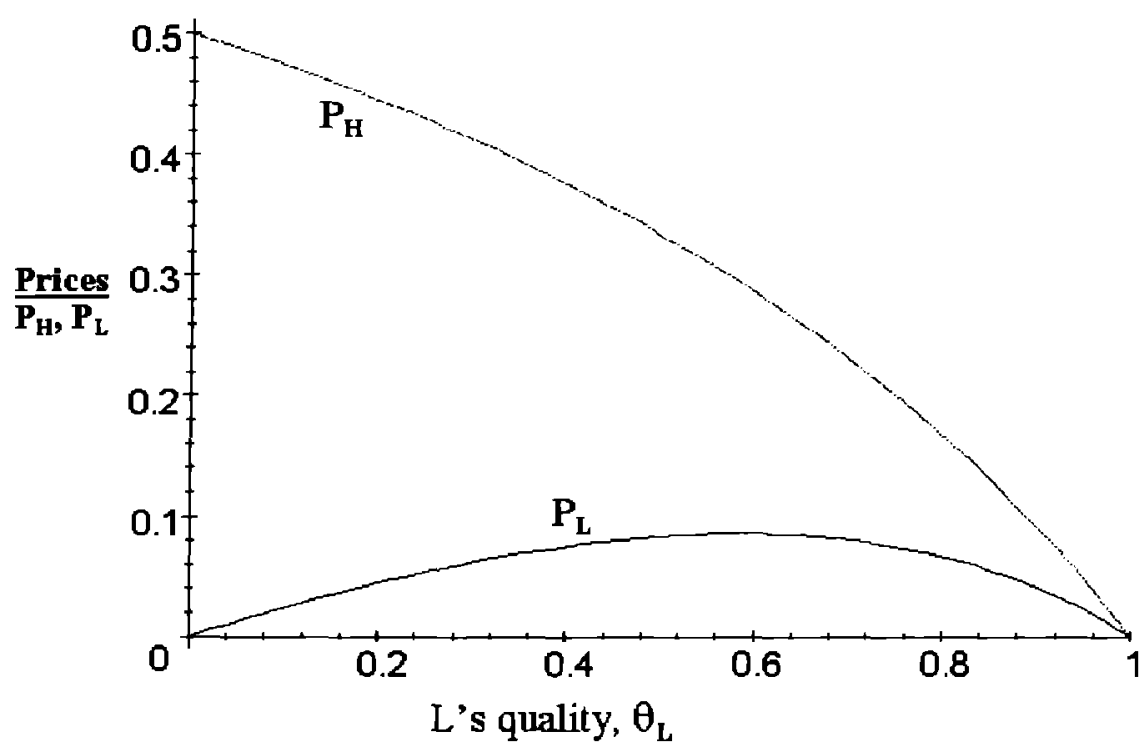

Notes: $P_{H}$ and $P_{L}$ are the prices for $\mathrm{H}$ and $\mathrm{L}$, respectively. $\theta_{L}$ is $\mathrm{L}$ 's quality. The price curves are drawn for the case of $\theta_{H}=1$.

Substituting the equilibrium levels of $P_{H}$ and $P_{L}$ into the profit equations yields equilibrium profits of

$$
\pi_{H}=\frac{\theta_{H}\left(\theta_{H}-\theta_{L}\right)}{2\left(2 \theta_{H}-\theta_{L}\right)}
$$

and

$$
\pi_{L}=\frac{\theta_{H} \theta_{L}\left(\theta_{H}-\theta_{L}\right)}{4\left(2 \theta_{H}-\theta_{L}\right)^{2}}
$$

Figure 2 plots equilibrium profits against $\theta_{L}$ for the case of $\theta_{H}=1$. As expected, $\pi_{H}$ falls monotonically with $\theta_{L}$ as $H$ faces greater and greater competition. The relationship of $\pi_{L}$ and $\theta_{L}$ is more interesting, and is similar to the relationship of $P_{L}$ and $\theta_{L}$. At first, $\pi_{L}$ increases with $\theta_{L}$, as L is able to charge higher prices without losing market share. Eventually, as L's 


\section{Figure 2 - Profits for H and L as a Function of L's Quality}

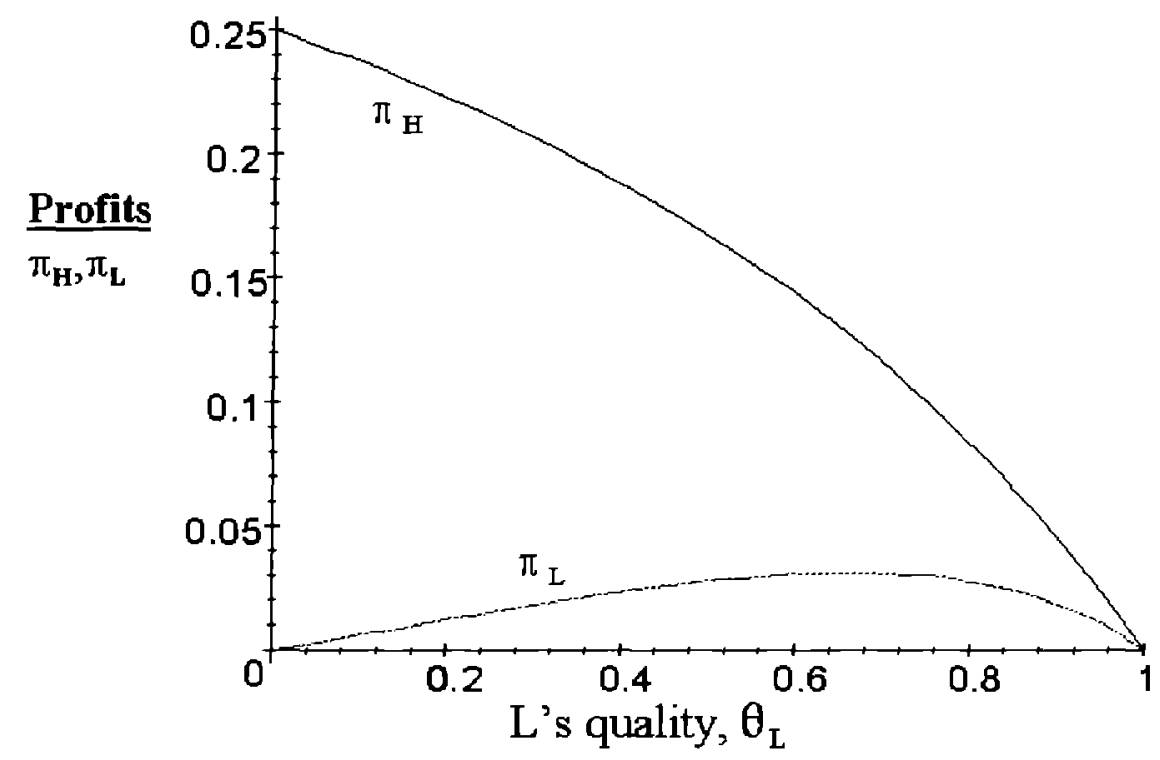

Notes: $\pi_{H}$ and $\pi_{L}$ are profits for $\mathrm{H}$ and $\mathrm{L}$, respectively. $\theta_{L}$ is L's quality. The profit curves are drawn for the case of $\theta_{H}=1$.

quality closes in on H's, the price competition becomes so intense that $P_{H}$ and $P_{L}$ both fall to low levels, making $\pi_{L}$ diminish. As $\theta_{L} \rightarrow 1=\theta_{H}$, prices and profits go to zero for both firms.

A major focus of this paper is the relative market shares of high- and low-quality sellers. What will be the equilibrium ratio of sales for $\mathrm{H}$ and $\mathrm{L}$ ? We denote this ratio as $r$, where

$$
r=\frac{Q_{L}}{Q_{H}}=\frac{\left(\frac{P_{H}-P_{L}}{\theta_{H}-\theta_{L}}-\frac{P_{L}}{\theta_{L}}\right)}{\left(1-\frac{P_{H}-P_{L}}{\theta_{H}-\theta_{L}}\right)} .
$$

Many of our results can be expressed in terms of $\frac{\theta_{L}}{\theta_{H}}$, the ratio between the two qualities. Therefore, we employ the notation

$$
\alpha=\frac{\theta_{L}}{\theta_{H}} .
$$

Substituting our equilibrium values for $P_{H}$ and $P_{L}$ yields 


$$
r=\frac{1}{2-\alpha}
$$

Thus, (16) reveals that the ratio of L's and H's market shares is a function of the ratio of their qualities, with an upper bound of 1 (when $\alpha=1$ ) and a lower bound of $\frac{1}{2}$ (when $\alpha=0$ ). Two main results follow directly from (16).

Result 1: $H$ always has a greater market share than $L: r<1, \forall \alpha$.

Result 2: The ratio of the market shares increases with the ratio of the qualities: $\frac{\partial r}{\partial \alpha}=$ $\frac{1}{(2-\alpha)^{2}}>0$.

These two results serve as simple benchmarks for the analyses that follow.

\section{Convex Costs of Production}

We now bring costs into the basic model, employing a simple formulation for the cost function, $F\left(Q_{m}\right)$, of

$$
F\left(Q_{m}\right)=\frac{c Q_{m}^{2}}{2}
$$

which implies marginal costs for each firm of

$$
F^{\prime}\left(Q_{m}\right)=c Q_{m}
$$

A price-taking firm with this total cost function would have a linear supply curve with slope $=c$. Overall, a market composed of a fixed number of such firms with some quality level $\theta_{m}$ and the continuum of consumers with the preferences given in section 2 would generate linear supply and demand curves. ${ }^{12}$

The inclusion of costs does not alter the consumers' problem; their optimal decision rules are the same as in section 2. As before, $\mathrm{H}$ sets her price first by maximizing

\footnotetext{
$1 \overline{2}$ Solutions to a model with different marginal costs for each firm and to a model with linear total costs are available from the authors. Results for these models are qualitatively similar to those described in this section.
} 


$$
\pi_{H}=\left(1-\frac{P_{H}-P_{L}}{\theta_{H}-\theta_{L}}\right) P_{H}-\frac{c\left(1-\frac{P_{H}-P_{L}}{\theta_{H}-\theta_{L}}\right)^{2}}{2},
$$

and then $\mathrm{L}$ sets his price by maximizing

$$
\pi_{L}=\left(\frac{P_{H}-P_{L}}{\theta_{H}-\theta_{L}}-\frac{P_{L}}{\theta_{L}}\right) P_{L}-\frac{c\left(\frac{P_{H-P_{L}}}{\theta_{H}-\theta_{L}}-\frac{P_{L}}{\theta_{L}}\right)^{2}}{2} .
$$

We solve this game backwards to obtain equilibrium levels for prices and quantities as a function of the parameters. A bit of algebra reveals that

$$
r=\frac{\theta_{L}\left(2 \theta_{L} \theta_{H}^{2} 0-2 \theta_{L}^{2} \theta_{H}+c \theta_{H}^{2}-c \theta_{L}^{2}+2 c \theta_{L} \theta_{H}+c^{2} \theta_{H}\right)}{4 \theta_{L}^{2} \theta_{H}^{2}+2 \theta_{L}^{4}-6 \theta_{L}^{3} \theta_{H}+4 c \theta_{L} \theta_{H}^{2}-3 c \theta_{L}^{2} \theta_{H}+c^{2} \theta_{H}^{2}} \cdot{ }^{13}
$$

The main results here can be stated analogously to those of section 2 .

Result $1^{\prime}: L$ can have a larger market share than $H: r>1$ for some values of $c, \theta_{H}$, and $\theta_{L}$

Interestingly, once we add even a small level of convex costs, it is sometimes optimal for $\mathrm{H}$ to set a high price, attract a small number of high-value customers, and let $\mathrm{L}$ take a. majority of the market. This result is depicted graphically in Figure 3, which plots $r$ against $\theta_{L}$ for the case where $c=.1, \theta_{H}=1$.

This figure demonstrates the dangers of ready conjectures about the relationship between market share and quality. Even in this simple example, the high-quality producer will sometimes sell more and sometimes less than the low-quality producer. It is important to remember here that the consumer valuations are uniformly distributed; the result is not driven by H's desire to capture a slender tail of high-value consumers. As costs rise, both $\mathrm{H}$ and L select higher prices, resulting in lower quantities, but $\mathrm{H}$ raises price at a faster rate.

Result $2^{\prime}:$ The ratio of the market shares increases with $\theta_{L}$ and decreases with $\theta_{H}: \frac{\partial r}{\partial \theta_{L}}>0$ and $\frac{\partial r}{\partial \theta_{H}}<0$.

13 See the Appendix for details. 


\section{Figure 3 - The Market Share Ratio of L and H as a Function of L's Quality}

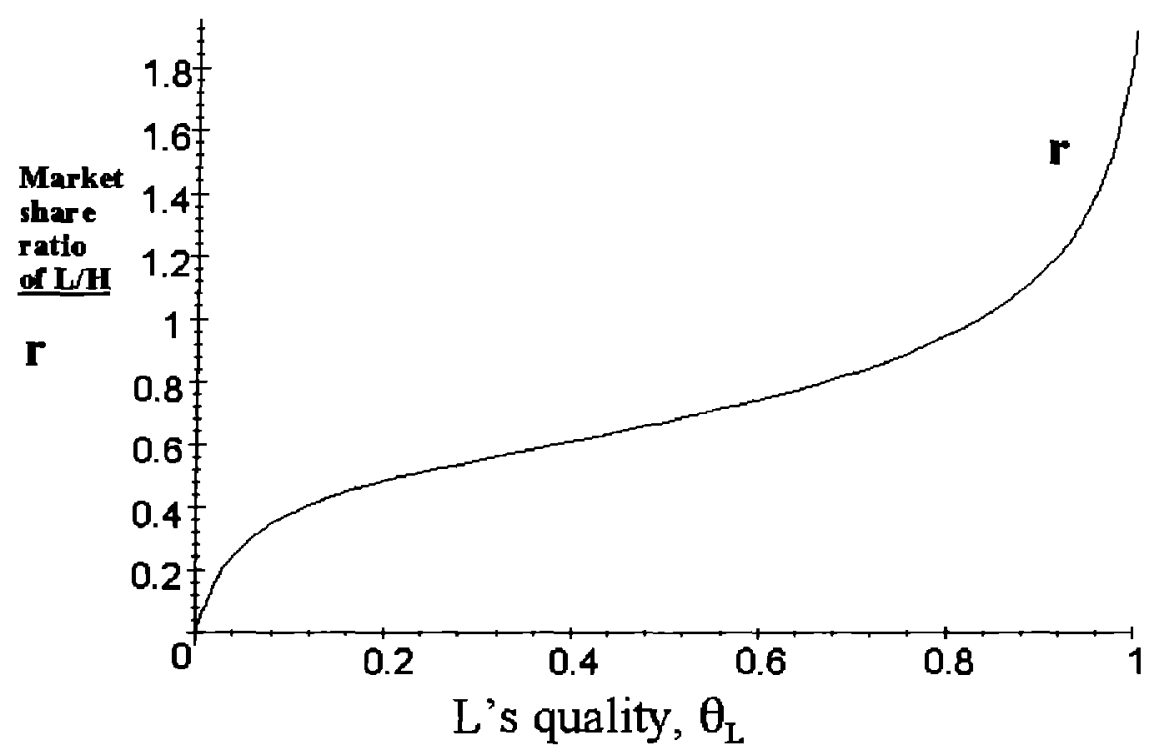

Notes: $r$ is the ratio of L's quantity to H's quantity. $\theta_{L}$ is L's quality. The curve is drawn for the case of $\theta_{H}=1$.

This is analogous to Result 2 from the previous section, although now we can no longer express $r$ purely in terms of $\alpha$. Figure 3 shows the typical relationship: ${ }^{14} r$ starts off very low when $\theta_{L}$ is low, and then rises monotonically with $\theta_{L}$, passing through $r=1$. That is, the market shares of both firms are increasing in their own quality. This is a logical comparative static result to expect, but it must be considered carefully in light of Result $1^{\prime}$. Together, the two results show that if a firm increases its quality, then its market share will also increase, but the higher-quality firm will not necessarily have the greater market share.

Figure 4 plots $r$ for the case of $\theta_{H}=1, \theta_{L}=.5$. As can be seen from the figure, $r$ first increases with $c$ and then decreases. In the limit, as $c$ goes to infinity, $r$ converges to $\alpha=\frac{\theta_{L}}{\theta_{H}}$, which is equal to .5 in this case. Since $r$ is a continuous function of $c$, it is reasonable to abstract from costs with at least some confidence that any specific solution to the game will not be made unstable by small perturbations in costs. Nevertheless, the

$1 \overline{4}$ See the Appendix for details. 
Figure 4 - Market Share Ratio Between $\mathrm{L}$ and $\mathrm{H}$ as a Function of the Slope of the Marginal Cost Curve

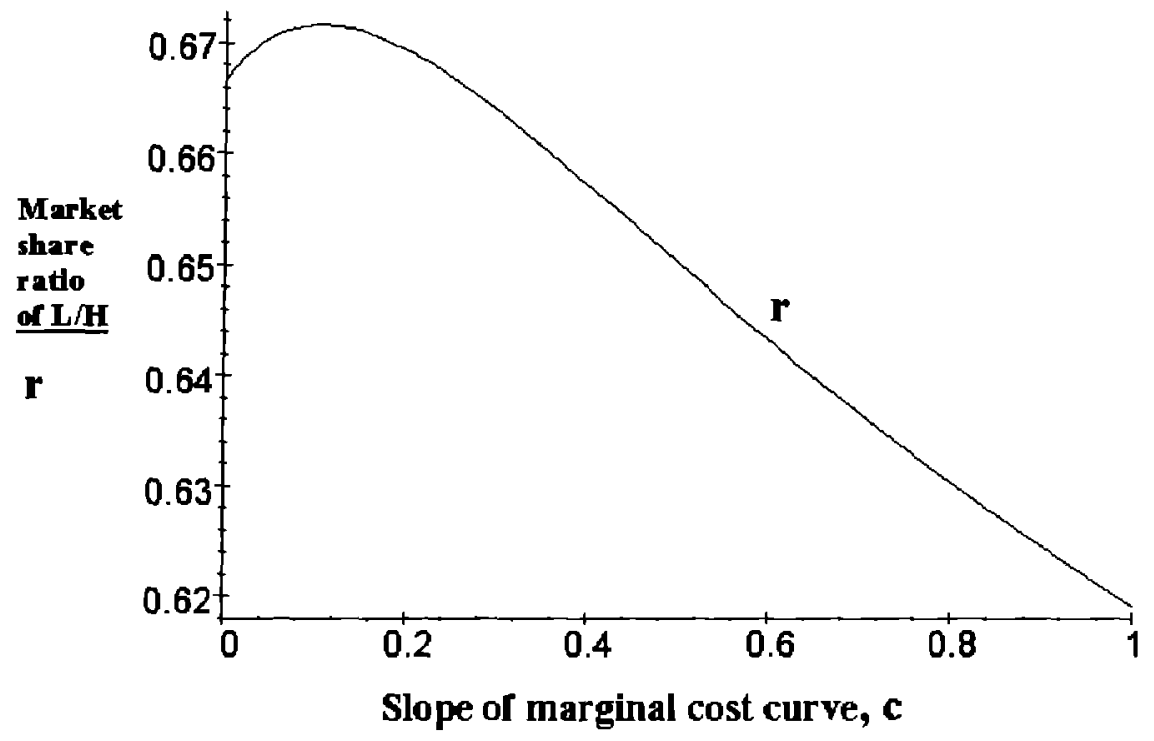

Notes: $r$ is the ratio between L's quantity and H's quantity. $\mathrm{c}$ is the slope of the marginal cost curve. The curve is drawn for the case of $\theta_{H}=1$.

results of this section teach us to be wary of broad conjectures about the set of all equilibria based on no-cost models. With these caveats in mind, the next section presents a model with imperfect information and no costs of production.

\section{Imperfect Information}

For many goods and services, it is difficult or impossible for some consumers to know the true quality of an item before purchase. For example, a consumer would not necessarily be able to ascertain the quality of the wiring installed by an electrician until some time passed after the job was completed. This section uses a very simple information structure for consumers who are trying to distinguish between $\mathrm{H}$ and $\mathrm{L}$; we separate consumers into two types, connoisseurs and dilettantes. A connoisseur can always tell producers apart; 
that is, a connoisseur will always know the type of producer that he or she is buying from. A dilettante can only tell producers apart if they are charging different prices. If the two producers are charging the same price, then the dilettante will be unable to distinguish $\mathrm{H}$ from $\mathrm{L}$, at least until after the purchase. Our model allows dilettantes to deduce information when different prices are charged since quality may be learned much more easily in markets where prices convey information. Thus, if quality were either positively or negatively related to price we assume that this fact would invariably be known. When prices are the same, additional work is required to determine who is high quality and who is low. Dilettantes are capable of costlessly using price-dependent information, such as that "the no-load mutual funds have the highest returns", but unable (except at prohibitive cost) to use non-pricedependent information, such as that "mutual funds that invest primarily in stocks with low price-to-earnings ratios have the highest returns". There is nothing about this information structure that is inconsistent with dilettantes being rational utility maximizers, and we model them as such.

We denote the fraction of dilettantes by $\lambda$, where dilettantes are drawn uniformly from all consumers. ${ }^{15}$ Since connoisseurs can always tell the producers apart, the conditions for their purchase decision are the same as in section 2. If the producers set different prices, then dilettantes can tell them apart as well, and their purchase decisions will be the same as those of the connoisseurs. However, if producers set the same price, then a dilettante will have to randomly choose a producer (one-half chance of each), and will only purchase the good if his expected utility of this random purchase is nonnegative. More formally, when facing a single price, $P$, a dilettante will

(1) buy if $\left(\frac{\theta_{H}+\theta_{L}}{2}\right) v \geq P$; and

(2) otherwise not buy.

When it is L's turn to set prices, he knows that he can choose either a pooling equilibrium

15 This assumption seems most reasonable for markets such as automobiles, where both dilettantes and connoisseurs may care equally about quality factors like safety and reliability, even though connoisseurs would be better informed. Nevertheless, relaxing this assumption and drawing connoisseurs more heavily from "high $v$ " consumers would not qualitatively change the results. 
(same price as $\mathrm{H}$ ), or a separating equilibrium (different price). If he chooses a separating equilibrium, then all consumers will be able to tell the producers apart, and his profits will be the same as they were in the model studied in section 2 . Let the superscripts $p$ and $s$ indicate pooling and separating, respectively. Then L's profits are

$$
\pi_{L}^{s}=\left(\frac{P_{H}-P_{L}}{\theta_{H}-\theta_{L}}-\frac{P_{L}}{\theta_{L}}\right) P_{L}
$$

Profits will be maximized here by a choice of $P_{L}$ of

$$
P_{L}=\frac{\alpha P_{H}}{2}
$$

which is the same as the solution in section 2 , this time written in terms of $\alpha$. A change of variables here of

$$
\beta=\theta_{H}-\theta_{L}
$$

enables us to write our results more concisely. For example, optimal separating profits for L will be given by

$$
\pi_{L}^{s}=\frac{\alpha P_{H}^{2}}{4 \beta}
$$

If $\mathrm{L}$ chooses a pooling price, $P_{L}=P_{H}$, then his profits will be

$$
\pi_{L}^{p}=\frac{\lambda}{2}\left(1-\frac{2 P_{H}}{\theta_{H}+\theta_{L}}\right) P_{H}
$$

There is no maximization here, since there is only one price, $P_{L}=P_{H}$, at which there will be pooling. If $\mathrm{L}$ selects the pooling price, he will only sell to dilettantes who have a positive expected value of purchasing the good. Half of these dilettantes (by chance) will choose H, and half will choose L. This process will be familiar to tourists who have tried to pick a Broadway show from the listings in the New York Times.

L's decision, then, is whether to choose the separating profits given in (24) or the pooling profits given in (25). He will choose the separating profits, and a separating equilibrium will result if $\pi_{L}^{s} \geq \pi_{L}^{p}$. This condition implies that 


$$
P_{H} \geq \frac{2 \lambda \beta(1+\alpha)}{\alpha(1+\alpha)+4 \lambda(1-\alpha)} .
$$

That is, there will be a cutoff level for $P_{H}$, above which $\mathrm{L}$ will always prefer to separate; below the cutoff level $\mathrm{L}$ will prefer to pool; and at the cutoff level he will be indifferent. The intuition for this is straightforward: L's optimal separating price is always a proportion of $P_{H}$, so when $P_{H}$ is low, L's separating profits will be low as well.

\section{Figure 5 - L's Profits for Pooling and Separating as a Function of H's Price}

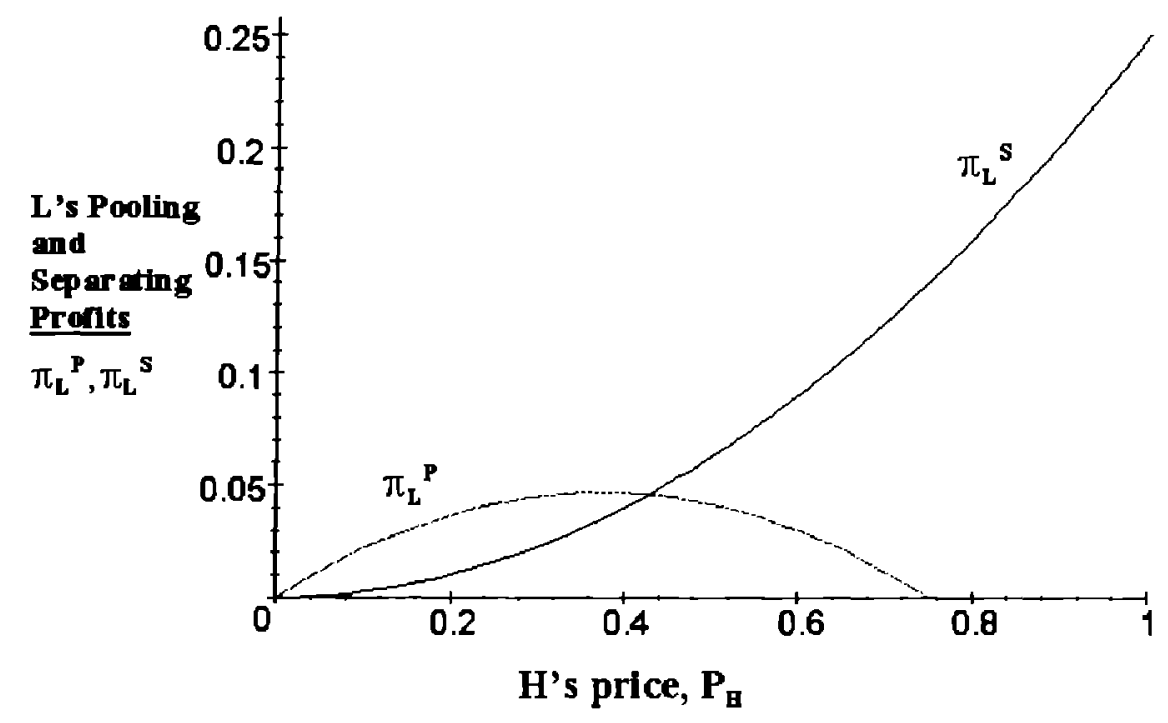

Notes: $\pi_{L}^{s}$ is L's profit if he chooses the optimal separating price to $P_{L}$ (eq. 24). $\pi_{L}^{p}$ is L's profit if he chooses to pool by choosing $P_{L}=P_{H}$ (eq. 25). The profits curves are drawn for the case $\lambda=.5, \theta_{H}=1$ and $\theta_{L}=.5$ (i.e. $\alpha=\beta=.5$ ).

Figure 5 shows the optimal separating profits compared to pooling profits as a function of $P_{H}$ for the special case of $\lambda=.5, \theta_{H}=1$ and $\theta_{L}=.5$ (i.e., $\alpha=\beta=.5$ ). As $P_{H}$ rises, separating profits rise monotonically, while pooling profits first rise and then fall as is typical for a monopoly. Pooling profits reach their maximum when demand for the pooled product is unit elastic. The two curves intersect at $P_{H}^{*}=\frac{2 \lambda \beta(1+\alpha)}{\alpha(1+\alpha)+4 \lambda(1-\alpha)}=\frac{.5(1.5)}{.5(1.5)+2(.5)}=.42857$. For 
low levels of $P_{H}, \mathrm{~L}$ is better off pooling, because the low price set by $\mathrm{H}$ does not leave much room for $\mathrm{L}$ to earn profits by attracting low $v$ customers with a still lower price.

The next step is to solve for H's optimal $P_{H}$, given L's known optimal response. $\mathrm{H}$ knows that she can bring about either a pooling or separating equilibrium, depending on her choice of $P_{H}$. We find her optimal price by solving for her maximum profits in each type of equilibrium, and then comparing the two.

To choose a separating equilibrium, $\mathrm{H}$ must maximize

$$
\begin{gathered}
\pi_{H}^{s}=\left(1-\frac{P_{H}-\frac{\alpha P_{H}}{2}}{\beta}\right) P_{H}, \\
\text { subject to } P_{H} \geq \frac{2 \lambda \beta(1+\alpha)}{\alpha(1+\alpha)+4 \lambda(1-\alpha)} .
\end{gathered}
$$

The constraint must be included because if $\mathrm{H}$ chooses a $P_{H}$ that is too low, then $\mathrm{L}$ will choose to pool.

To attain optimal pooling profits, $\mathrm{H}$ must maximize

$$
\begin{aligned}
\pi_{H}^{p}= & (1-\lambda)\left(1-\frac{P_{H}}{\theta_{H}}\right) P_{H}+\frac{\lambda}{2}\left(1-\frac{2 P_{H}}{\theta_{H}+\theta_{L}}\right) P_{H} \\
& \text { subject to } P_{H} \leq \frac{2 \lambda \beta(1+\alpha)}{\alpha(1+\alpha)+4 \lambda(1-\alpha)} .
\end{aligned}
$$

The first term in the profit equation derives from the demand by connoisseurs. Since all connoisseurs who choose to purchase the good will do so from $\mathrm{H}$, the lower bound for $v$ buying high-quality goods will be $\frac{P_{H}}{\theta_{H}}$, instead of $\frac{P_{H}-P_{L}}{\beta}$, as it was in sections 2 and 3 . The second term comes from the demand by dilettantes. Finally, the constraint ensures that H chooses a price low enough that L will actually choose to pool. We say that a pooling [separating] equilibrium is "constrained" if H's profits cannot be pushed higher without inducing $\mathrm{L}$ to separate [pool].

If H's separating profits (solution to (27)) are higher than her pooling profits (solution to (28)), than she will choose the higher price in a separating equilibrium. If separating profits are lower, then she will choose a pooling equilibrium, and quality will beget quantity. 
Proposition 1: If quality levels are sufficiently close and dilettantes comprise a sufficient proportion of consumers, then only pooling equilibria will exist. Sufficient conditions here are the set $\alpha \geq .55 \cap \lambda \geq \frac{1+\alpha}{6-2 \alpha}$.

Proof: See Appendix.

Whenever the duopolists have qualities that are relatively close, we may be confident of a pooling equilibrium. The intuition is simple: as qualities converge - as $\alpha$ gets higher - competition becomes more intense in the separating equilibrium as both firms set prices lower, and profits fall for both. In the limit, profits will be zero, in effect due to a sequentialchoice variant of Bertrand competition. Thus, $\mathrm{H}$ has an incentive to try to reduce this competition by avoiding the low-profit separating equilibrium. She does this by holding prices so low that L might as well engage in a pooling equilibrium.

Graphical depictions are useful in reinforcing the intuition supporting the proposition. Figures 6 and 7 show separating profits, $\pi_{H}^{s}\left(\pi_{H}^{\bar{s}}\right.$ when constrained) and pooling profits, $\pi_{H}^{p}$ $\left(\pi_{H}^{\vec{p}}\right.$ when constrained) as a function of $\lambda$.

In Figure $6, \theta_{L}=.75$, and thus $\alpha=.75$ and $\beta=.25$. This is the typical case for the range of parameters used in Proposition 1. In both Figures 6 and 7, separating profits are constrained after the point of tangency between $\pi_{H}^{s}$ and $\pi_{H}^{\bar{s}}$; before that point, separating profits are equal to $\pi_{H}^{s}$, and after that point they are equal to $\pi_{H}^{\bar{s}}$. Pooling profits, however, are constrained before the tangency point of $\pi_{H}^{p}$ and $\pi_{H}^{\bar{p}}$; before that point, pooling profits are $\pi_{H}^{\bar{p}}$, and after that point they are equal to $\pi_{H}^{p}$. In Figure 6 , this latter tangency does not occur until $\lambda$ is approximately equal to 1 , so pooling profits are constrained for almost the entire range.

In Figure $6, H$ 's pooling profits, $\pi_{H}^{\bar{p}}$, become greater than separating profits at $\lambda \approx .2$, and stay greater than separating profits for the rest of the range. Therefore, only pooling equilibria will exist for all $\lambda>2$. Strikingly, with a sufficient proportion of dilettantes, $H$ sets a price low enough to induce L to pool. Yet L's market share can be very low in the pooling equilibrium. For example, when dilettantes and connoisseurs are equal in number, $\lambda=.5, \mathrm{~L}$ gets only one-quarter of the market, $r \approx .25$, as he will get one-half of the 
Figure 6 - H's Profits for Pooling and Separating as a Function of the Proportion of Dilettantes

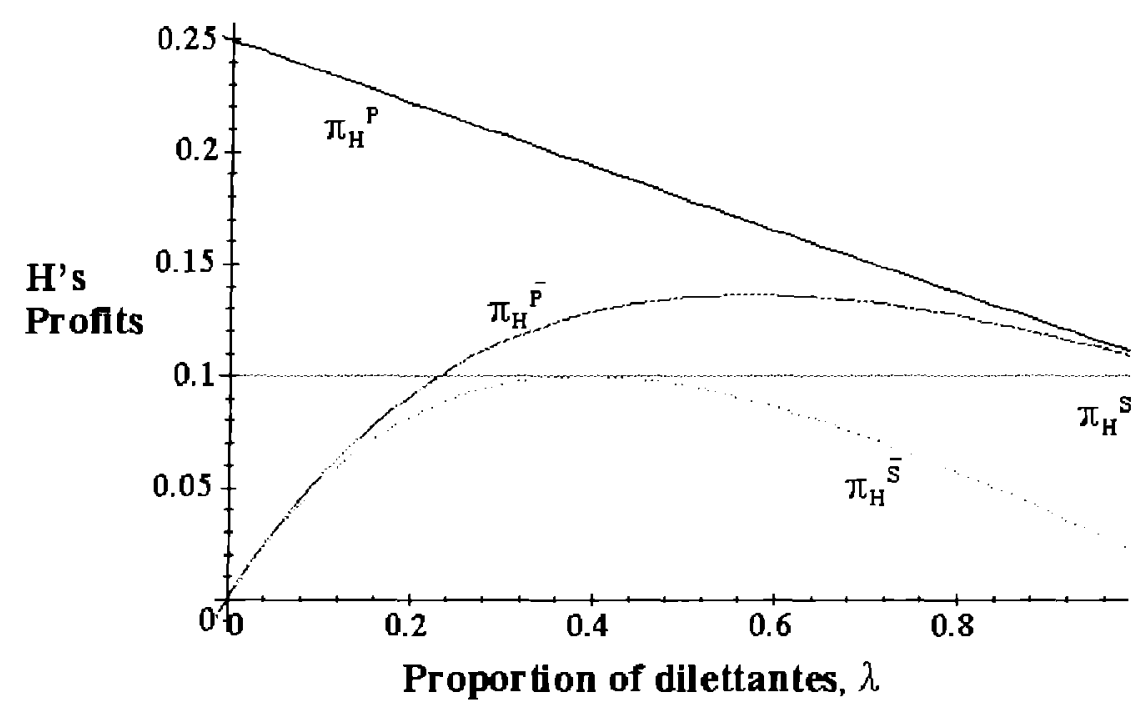

Notes: The profit curves are drawn as a function of $\lambda$ for the case of $\theta_{H}=1, \theta_{L}=.75(\alpha=.75, \beta=.25)$. The equations for the curves are given in the Appendix - with the equation numbers given below. $\pi_{H}^{s}$ is H's profit when $P_{H}$ is set at the opimal separating price and L chooses to separate (Eq. 45). $\pi_{H}^{\bar{s}}$ is H's profit when $P_{H}$ is set at the optimal price that makes $\mathrm{L}$ indifferent between pooling and separating, and $\mathrm{L}$ chooses to separate (Eq. 46). $\pi_{H}^{p}$ is H's profit when $P_{H}$ is set at the optimal pooling price and L chooses to pool (Eq. 51) - $\pi_{H}^{\bar{p}}$ is H's profit when $P_{L}$ is set at the optimal price that makes $\mathrm{L}$ indifferent between pooling and separating, and $\mathrm{L}$ chooses to pool (Eq. 52).

dilettantes, leaving all of the connoisseurs for $\mathrm{H}$. The two producers will charge the same price but sell vastly different quantities.

The result that drives $H$ to choose a pooling equilibrium is the intense competition that exists between the two firms as their qualities converge. With dilettantes sufficiently common, $\mathrm{H}$ has an opportunity to avoid this competition: by holding her price sufficiently low, she is sometimes able to induce L to pool, and thereby pick up all the business of connoisseurs. Although $\mathrm{H}$ sells at a lower price than she would in a separating equilibrium, she secures a far higher market share. L would be far better off at many pairs of separating prices; however, at the price chosen by $\mathrm{H}$, the best that $\mathrm{L}$ can do is to pool. 
Figure 7 - H's Profits for Pooling and Separating as a Function of the Proportion of Dilettantes

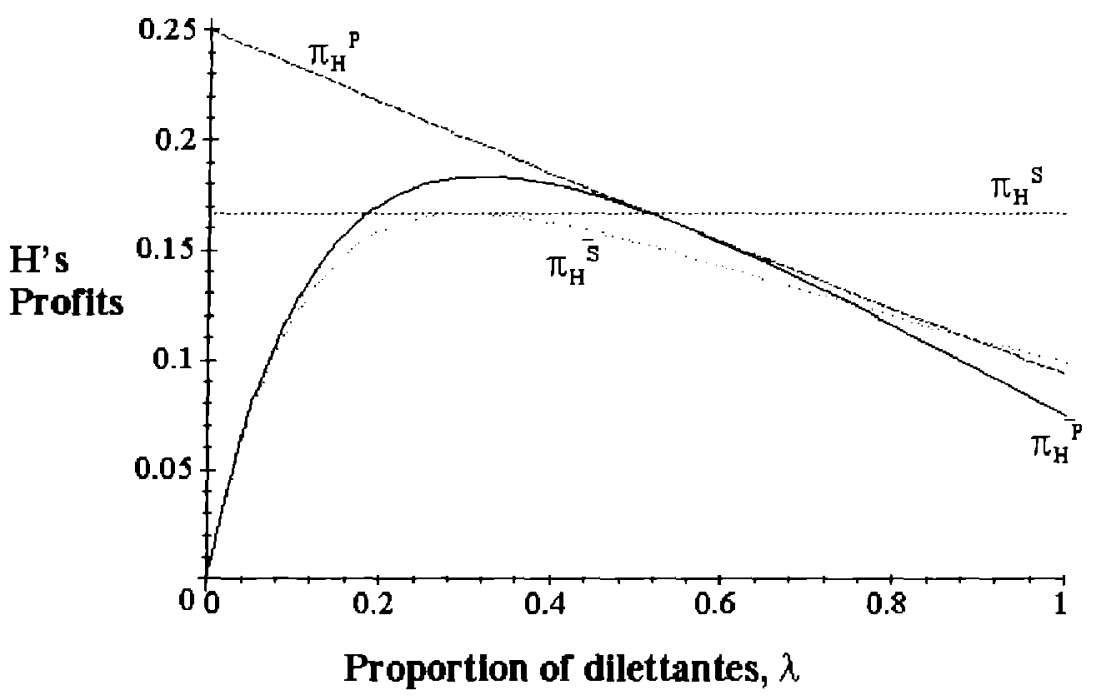

Notes: The profit curves are drawn as a function of $\lambda$ for the case of $\theta_{H}=1, \theta_{L}=.5(\alpha=.5, \beta=.5)$. The equations for the curves are given in the Appendix - with the equation numbers given below. $\pi_{H}^{s}$ is H's profit when $P_{H}$ is set at the opimal separating price and $\mathrm{L}$ chooses to separate (Eq. 45). $\pi_{H}^{\bar{s}}$ is $\mathrm{H}$ 's profit when $P_{H}$ is set at the optimal price that makes $\mathrm{L}$ indifferent between pooling and separating, and $\mathrm{L}$ chooses to separate (Eq. 46). $\pi_{H}^{p}$ is H's profit when $P_{H}$ is set at the optimal pooling price and $\mathrm{L}$ chooses to pool (Eq. 51). $\pi_{H}^{\bar{p}}$ is H's profit when $P_{L}$ is set at the optimal price that makes $\mathrm{L}$ indifferent between pooling and separating, and $\mathrm{L}$ chooses to pool (Eq. 52).

Figure 7 shows the necessity of the lower bound on $\alpha$ in Proposition 1. Here, $\theta_{L}=.5$ (and, thus, $\alpha=\beta=.5$ ). In this case, $\pi_{H}^{\bar{s}}$ becomes greater than $\pi_{H}^{p}$ after about $\lambda \approx .9$, even though pooling profits are unconstrained and separating profits are constrained. For these parameter values, we see a separating equilibrium at low levels of $\lambda$, a pooling equilibrium from about .2 to .9 , and then a separating equilibrium once again at the top of the range.

Surprisingly, a separating equilibrium exists when almost all the consumers are dilettantes. In the figure, H's profits in the pooling equilibrium fall faster with the proportion of dilettantes than they do in the constrained separating equilibrium. (This can be seen in the figure by comparing the slopes of $\pi_{H}^{p}$ and $\pi_{H}^{\bar{s}}$.) When the proportion of dilettantes becomes very high $(\lambda \approx .9$ in Figure 7$)$, it is no longer worthwhile for $\mathrm{H}$ to allow pooling, since she 
gets only slightly more than half the total consumers. Instead, she sets a price sufficiently high that $\mathrm{L}$ does even better by separating. This outcome is not possible when the qualities become too close, because $\mathrm{H}$ no longer does well enough in the separating equilibrium.

We present the analogues to Results 1 and 2 from section 2. Both follow as corollaries of Proposition 1.

Result $1^{\prime \prime}: L$ can have a larger market share than $H: r>1$ for some values of $\lambda, \theta_{H}$, and $\theta_{L}$

This can occur when $H$ is at a constrained separating equilibrium. For example, in the case of $\alpha=.5, \lambda=1, \mathrm{H}$ will choose a separating equilibrium and will obtain only one-quarter of the market; that is, $r=3$. See the Appendix for details of this calculation.

Result $2^{\prime \prime}:$ The ratio of the market shares can decrease when the ratio of the qualities increases: $r\left(\alpha_{1}\right)>r\left(\alpha_{2}\right), \alpha_{2}>\alpha_{1}$, for some values of $\lambda$.

This will occur when an increase in $\alpha$ causes $H$ to change to a pooling from a separating equilibrium. At this point, $r(\alpha)$ will not be differentiable. One simple example of such a change would be an increase in $\alpha$ from .5 to .6 when $\lambda=1$. When $\alpha=.5, \mathrm{H}$ chooses to separate and (as in Result $1^{\prime \prime}$ ) $r=3$; for $\alpha=.6$, the conditions of Proposition 1 are met and we obtain a pooling equilibrium with $r=1$.

Results $1^{\prime \prime}$ and $2^{\prime \prime}$ are quite different than Results 1 and 2 of section 2; allowing for imperfect information can radically change equilibria in models of vertical differentiation. Even our stylized type of imperfect information can provide rich results and insights into mechanisms that allow markets to clear with sellers providing vastly different quantities than they would under perfect information.

\section{Two Empirical Examples: Mutual Funds and Automobiles}

Our theory predicts that when significant numbers of consumers have difficulty discerning quality, goods of different qualities but similar production costs may be offered at the same price in a market. The higher quality goods will sell more, since knowledgeable consumers, 
our connoisseurs, are able to discern differences. This theory would be reinforced if we could identify markets where goods of different quality sell at the same price and the high-quality goods sell higher quantities.

We examined two major U.S. industries - equity mutual funds and automobiles - and analyzed cross-sectional relationships among proxies for price, quantity, and quality. The results of this section provide empirical motivation and support for the model presented in section 4 .

\subsection{Mutual Funds}

The oldest question in the academic literature on equity mutual funds, still hotly debated, concerns the ability of funds and fund managers to earn consistent excess risk-adjusted returns. ${ }^{16}$ If such excess returns relative to the market are possible, then fund "quality" would be a valuable construct; if not, then the search for quality is fruitless. In any event, both consumers and funds pay enormous attention to performance measures and quality rankings, ${ }^{17}$ and at least until the academic debate is settled, such ratings are likely to play a large role in funds' and consumers' behavior. Therefore, we take performance measures as a proxy for quality, be it real or imagined. Our goal is not to add anything to the debate about the usefulness of these proxies, but simply to estimate their effects on price and quantity.

The universe of funds for our study consists of the 982 U.S. domestic diversified equity mutual funds for which data on all the following variables is available: ${ }^{18}$

Price - Mutual funds can charge a price in different ways. To assure consideration of each possibility, we employ three different proxies for price.

(A) The percentage "load", or charge, paid to the fund. The load is calculated and paid either on the original investment ("front load") or on the asset value when the investor exits the fund ("deferred load"). These loads may sometimes be reduced for large or long-term investors; we use the figures published in the funds' prospectuses.

\footnotetext{
16 See Hendricks, Patel, and Zeckhauser (1993), Brown and Goetzman (1995), and Malkiel (1995) for some recent work on this question. These excess returns may be measured relative to the market as a whole or relative to the universe of mutual funds. In either case, it is the persisitence and predictability of excess returns that matters.

17 For evidence on the attention paid to performance measures, see Chevalier and Ellison (1995) and Brown, Harlow and Starks (1996).

18 All data was obtained from the Morningstar Inc. Ascent and Principia databases.
} 
(B) The marketing/administrative ("12b-1") fee paid annually by all fund investors. This fee is capped by law at a maximum of 1 percent.

(C) The funds' total expense ratio - total expenses divided by assets under management. Total expenses include the $12 \mathrm{~b}-1$ fee, but not brokerage (transaction) costs. Total expenses sometimes include incentive bonuses to the fund's management for meeting certain targets. We can think of these expenses as more than simply covering basic costs.

Quantity - Quantity is represented by net inflows into the fund from January 31, 1996, to April 30, 1996. These inflows are calculated as

$$
N I_{i}=A_{a p r i l, i}-A_{j a n, i}\left(1+R_{i}\right),
$$

where $N I_{i}=$ net inflows into fund $i$ from January 31 to April 30, 1996, $A_{\text {april, } i}=$ total assets under management for fund $i$ as of April 30,1996, $A_{j a n, i}=$ total assets under management for fund $i$ as of January 31, 1996, and $R_{i}=3$-month return from January 31 to April 30, $1996 .{ }^{19}$

Quality - 3-year annualized return, January 31, 1993, to January 31, 1996. This is the actual return that investors received; it is net of expenses. We discuss below the effect of adding back expenses and using gross returns as the quality variable.

The dependent variables we explore are the load, $L$; the $12 \mathrm{~b}-1$ fee, $12 b 1$; the expense ratio, $E R$; and net inflows, $N I$. The three-year annualized return, $R 3$, is an independent variable. Table 1 summarizes the results.

Regressions 1A, 1B, and 1C show the results of regressing price on quality (i.e., three-year return) for our three different price proxies. In the following discussions, "significant" always means "statistically different from zero at the five-percent level", unless otherwise noted. In regression \#1A, load is regressed on quality. The coefficient on quality is not significant. ${ }^{20}$ Regression $1 \mathrm{~B}$, with the $12 \mathrm{~b}-1$ fee as the price variable, has the same result. When we use expense ratio as the price proxy in regression $1 \mathrm{C}$, we find the coefficient on quality to be

\footnotetext{
19 Note that this net inflow calculation will underestimate "true" inflows (= puchases - redemptions) because any dividends paid out by the fund, and not immediately reinvested, will appear to be an outflow in our calculation. We cannot correct for this, unfortunately, because data on dividends (or true inflows) is not readily available. This omission, and the bias it introduces, is discussed below. In any case, the bias should be very small, because our sample period does not include either the year-end or mid-year dividends.

20 The same result occurs for front load by itself or deferred load by itself as the the price variable.
} 
Table 1- Cross-Sectional Relationships among Price, Quality, and Quantity Proxies in the Market for U.S. Diversified Equity Mutual Funds

(1)

(2)

Reg. \# Dep. Var. $R 3$

(3)

(4)

(5)

(6)

(7)

(8)

\section{$1 \mathrm{~A}$}

$L$

.010

L

$12 b 1$

$E R$

Constant

$\mathrm{R}^{2}$

$1 \mathrm{~B}$

$12 b 1$

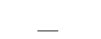

$-\quad 2.11$
$-\quad 11$

.000

$1 \mathrm{C}$

$E R$

2

$-.088$

$-$

.217

.000

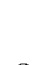

$N I$

$-$

- $\quad-$

2.46

.233

(.034)

3

$N I$

$.129 \quad .016$

(.041) (.070)

$\begin{array}{ll}.337 & -.223\end{array}$

(.625) (.238)

$4.98 \quad .018$

$4.98 \quad .019$

Notes: Table 1 reports the results of OLS regressions involving price, quantity, and quality proxies. The sample for each regression includes all 982 domestic diversified equity funds for which we could get reliable data for all included variables from Morningstar Inc.'s databases. Column (1) gives the regression \# as it is referred to in the text of the paper. (2) gives the dependent variable for each regression. Columns (3)-(6) report the coefficients on each included independent variable; standard errors for these estimates are given in parentheses. $N I$ are net inflows in the period January 31 to April 30, 1996, in \$millions $(\mu=1.02, \sigma=5.02) ; L_{i}$ is the total load $=$ front load + deferred load $(\mu=2.24, \sigma=2.28)$; $12 b 1_{i}$ is the $12 \mathrm{~b}-1$ (marketing/administrative) fee $(\mu=.21, \sigma=.30) ; E R$ is the expense ratio $(\mu=1.28, \sigma=.83) ; R 3$ is the annualized return for the three years preceding January 31 , $1996(\mu=13.42, \sigma=4.55)$. All units are percent unless otherwise noted. The text of the paper discusses each of these variables. Column (7) reports the constant and Column (8) reports the $\mathrm{R}^{2}$ for each regression. 
negative and significant. ${ }^{21}$ In none of these cases is there an indication that funds with

superior three-year performances set higher prices than other funds. The results are similar for other performance measures; for one-year, five-year, or ten-year annualized returns, there is no significant relationship between price and quality for proxies (A) and (B), and there is a significant negative relationship for proxy $(\mathrm{C})$.

The results of regression 2 show a clear positive relationship between quantity and quality. The coefficient on quality is positive and significant. The point estimate implies $\$ 9.23$ million in inflows for an additional one percentage point of three-year annualized returns. This would seem to be economically significant as well. Similar results are found using one-, five-, and ten-year returns as the quality variable. Our calculation of net inflows understates true inflows (purchases less redemptions) by the amount of nonreinvested dividends; since such dividends are likely to be positively correlated with returns, the effect of this underestimate should be to bias downward the coefficient on returns; adjusting for this bias would strengthen our results. As a further test, we reestimated regression 2 excluding all funds that have the investment objective of "income" or "growth and income" - the objectives most likely to have high dividends. The results were similar.

Regression 3 investigates the relationship between price and quantity. If some aspect of quality has not been captured by our performance measures, and this quality is positively correlated with both price and quantity, then we should be able to see evidence of this in regression 3, which regresses quantity on quality and all three of our price proxies. The results confirm the positive relationship between quantity and quality, and indicate no significant relationship between quantity and any of the price proxies. ${ }^{22}$

Overall, the market for diversified domestic equity mutual funds displays a positive relationship between quantity (as measured by net inflows), and quality (as measured by past returns.) There is no significant positive relationship between price (as measured by several

\footnotetext{
21 The quality variable is annualized returns, which is net of expenses. If we add back expenses so that the quality variable equals gross returns, we find the same results, including the significant negative coefficient when the expense ratio is regressed on returns. We do not have data on the breakdown of these expenses between advisory and nonadvisory expenses, but researchers working with more complete data sets have not found statistically significant positive relationships between either type of fee and gross returns. This is particularly surprising since advisory fees for some funds are directly linked to past returns. See Malkiel (1995).

22 This result also occurs if we include the three price proxies separately (results not reported here).
} 
proxies) and quality or price and quantity. This would certainly suggest that the predominant response of firms facing an increase in demand is not to raise their prices, but rather to sell more of their product.

Similar results have been found in other studies of financial services. Tufano (1989) finds that investment banks that create innovative products do not subsequently raise their prices, but rather capture a larger share of the underwriting market. Gompers and Lerner (1996) show that firm age and reputation explain large differences in size but only small and economically insignificant differences in price. Finally, Hulbert (1996) finds that price and past performance are uncorrelated for investment advisory newsletters.

\subsection{Automobiles}

With the automobile industry, as in the study of mutual funds, we seek only to identify simple relationships among prices, quantities, and quality. ${ }^{23}$ We study cars from the 1994 model-year. The "model" is the level of aggregation used throughout. For example, our data source listed six different versions of the Ford Escort in 1994, as well as many option packages that could be attached to each version. We simply consider the "Ford Escort". ${ }^{24}$ This aggregation is necessary given our data constraints. We use the following proxies:

Price - Automobile sales in the United States can be divided into wholesale and retail markets. First, manufacturers sell to dealers, who are by law independent of the manufacturers. The price charged to dealers is the "dealer cost" of an automobile, and is publicly available. Next, dealers sell to consumers. Manufacturer's publish a "suggested" price for these retail transactions, but the majority of purchases are the result of bargaining between dealer and consumer with a final price somewhere between the dealer cost and the manufacturer's suggested retail price. One can think of the retail automobile market as segmented by dealer cost, with cars competing within, but not between, cost segments. Within each segment, dealers compete by negotiating "prices" that are actually markups over dealer cost.

\footnotetext{
23 Among the recent academic works on the automobile industry are Berry, Levinsohn, and Pakes (1995) and Goldberg $(1995,1996)$. Bresnahan and Reiss (1985) study dealer markups in the automobile market; this is probably the most comparable study to ours.

24 The six versions of the Ford Escort are the 2-door hatchback, LX 2-door hatchback, LX 4-door hatchback, GT 2-door hatchback, LX 4-door sedan, and LX 4-door wagon. We describe below our method of choosing a single version to represent the model.
} 
Since dealer cost is common knowledge, it is best to use the markup as the relevant price variable. Then, dealer cost can be used as a proxy for the market segment. ${ }^{25}$

An optimal data set would include transaction prices for every vehicle, but such a data set was not available to us. Instead, we use published estimates of "target prices" calculated by The Complete Car Cost Guide (1994). These target prices are designed to give consumers an estimate of the price that they would actually have to pay for the car. It is based on a proprietary formula that takes into account typical dealer practices and supply and demand conditions in the market. ${ }^{26}$

The two price proxies that we use are markup variables derived from the published target prices and dealer costs.

(A) The target markup, $M_{i}$, given by

$$
M_{i}=T P_{i}-D C_{i}
$$

where $M_{i}=$ the markup on model $i, T P_{i}$ is the target price for model $i$, as given by The Complete Car Cost Guide, $D C_{i}$ is the dealer cost for model $i$ (from the same source); and

(B) The target markup ratio, $M R_{i}$, given by

$$
M R_{i}=\frac{M_{i}}{D C_{i}}
$$

The costs and target prices we use are those for the least expensive car of its model type. This is not a terribly restrictive method; although markups do differ across versions of the same model, the markup ratio is relatively constant. ${ }^{27}$

Quantity - Cars sold in the United States, in thousands. (Source: Ward's Automotive Yearbook 1994-95 (1994)).

Quality - Ratings from AutoTest (1994). Total ratings (out of a maximum of 190) are the sum of individual ratings in nineteen categories, each of which is graded from one to

\footnotetext{
25 Dealers will also sometimes receive rebates from manufacturers for each sale. These rebates are usually about one to two percent of the dealer cost. Unfortunately, the rebates may vary throughout the year, and we do not have reliable data on them for our sample. We discuss below the possible bias from this omission. 26 Private communication with the publisher.

27 For the six versions of the Ford Escort, the dealer cost ranges from $\$ 8,465$ to $\$ 11,436$, the target price from $\$ 9,000$ to $\$ 12,172$, the markup from $\$ 535$ to $\$ 736$, and the markup ratio from .063 to .064 . In each case, the lower bound is given by the 2-door hatchback (the version that we use to represent the model) and the upper bound is given by the GT 2-door hatchback.
} 
ten. ${ }^{28}$ These ratings and their index are subjective and certainly imperfect, but they were the best data we could find for our purposes.

As we did for mutual funds, we attempt to uncover the cross-sectional relationships among the variables. In addition to the variables discussed above, we also include dealer cost as a right-hand side variable in each of our regressions. The aim is to capture any quality effects after controlling for the correct cost segment of the market. (This was not an issue in our analysis of mutual funds.) Otherwise, the tests we do are direct analogues to those of the previous section.

Table 2 summarizes the findings of regressions $4 \mathrm{~A}, 4 \mathrm{~B}, 5$, and $6.4 \mathrm{~A}$ and $4 \mathrm{~B}$ regress the two price proxies (the markup in $4 \mathrm{~A}$ and the markup ratio in $4 \mathrm{~B}$ ) on the quality ratings and dealer cost. In neither case is the coefficient on quality significant. In $4 \mathrm{~A}$, the coefficient on cost is positive and significant. $4 \mathrm{~B}$ reinforces the evidence of a linear relationship between dealer cost and markup; it shows that the markup ratio (markup divided by dealer cost) is not a function of dealer cost. If there is any relationship between quality and the markup or markup ratio, then it is not captured by our quality proxy. ${ }^{29}$

Quantity is regressed on quality and dealer cost in regression 5. The coefficient on quality is positive and significant. The point estimate is economically significant: a one-point increase in the quality rating is associated with an increase of 3,410 in cars sold - this implies that more than 30,000 extra cars are sold for a one-standard deviation increase in the quality variable. By comparison, the median level of sales for our sample was 74,857 . As we found for mutual funds, quantity and quality seem positively correlated. ${ }^{30}$

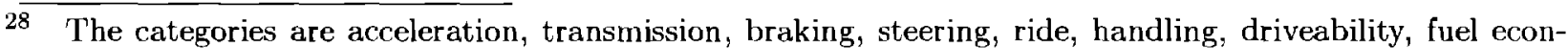
omy, comfort/convenience, interior room, driving position, instrumentation, controls, visibility, entry/exit, quietness, cargo space/liftover, exterior workmanship and interior workmanship. Auto Test (1994) also includes a category of "value", but we exclude it from our total due to its reliance on price. Thus, the original ranking are out of a maximum of 200 , and ours are out of a maximum of 190.

29 One weakness of using estimated target prices rather than real transaction data is that we are unable to measure the effect of stronger (or weaker) than expected sales on actual prices. On average, however, we would hope that sales forcasts and target prices are correct, so that our results reflect the planned price-quantity strategy of dealers.

30 Of course, since these quality ratings are subjective, we cannot be sure that they have not been influenced by the level of sales. In that case, as long as sales were autocorrelated, then simultaneous equations' bias would affect our results.
} 
Table 2- Cross-Sectional Relationships among Price, Quality, and Quantity Proxies in the Market for Automobiles in the U.S.

\begin{tabular}{cccccccc}
$(1)$ & $(2)$ & $(3)$ & $(4)$ & $(5)$ & $(6)$ & $(7)$ & $(8)$ \\
Reg. \# & Dep. Var. & $R A$ & $D C$ & $M$ & $M R$ & Constant & $\mathrm{R}^{2}$ \\
& & & & & & & \\
$4 \mathrm{~A}$ & $M$ & 2.37 & .067 & - & - & -404 & .755 \\
& & $(3.67)$ & $(.007)$ & & & & \\
$4 \mathrm{~B}$ & $M R$ & $9.85 \mathrm{E}-5$ & $4.20 \mathrm{E}-7$ & - & - & .042 & .056 \\
& & $(2.15 \mathrm{E}-4)$ & $(4.31 \mathrm{E}-7)$ & & & & \\
5 & \multirow{2}{*}{ SALES } & 3.41 & $-1.03 \mathrm{E}-2$ & - & - & 86.2 & .145 \\
& & $(1.65)$ & $(3.31 \mathrm{E}-3)$ & & & & \\
6 & \multirow{2}{*}{ SALES } & 3.49 & .014 & -.420 & $9.37 \mathrm{E}+3$ & -818 & .301 \\
& & $(1.53)$ & $(.012)$ & $(.187)$ & $(3.19 \mathrm{E}+3)$ & &
\end{tabular}

Notes: Table 2 reports the results of OLS regressions involving price, quantity and quality proxies. The sample includes 1994 model-year data for the 60 different models for which complete data was available. Hence, there are 60 observations in each regression. Cars classified as "sports" (as identified by AutoTest (1994)) and "luxury" (cars with DC> $\$ 25,000)$ are excluded. Column (1) gives the regression \# as it is referred to in the text of the paper. Column (2) gives the dependent variable for each regression. Columns (3)(6) report the coefficients on each included independent variable; standard errors for these estimates are given in parentheses. $R A$ is the rating, out of 190, for each car (Source: Auto Test; $\mu=148, \sigma=9$ ); $D C$ is the cost paid by dealers to manufacturers for each car, in dollars (Source: The Complete Car Cost Guide (1994), $\mu=14859, \sigma=4657$ ); $M$ is the "target" markup over cost, in dollars, according to The Complete Car Cost Guide $(\mu=946, \sigma=378) ; M R$ is the markup ratio, $\frac{M}{D C}(\mu=.063, \sigma=.011) ; S A L E S$ are the total sales in the U.S. for each model, in thousands (Source: Ward's Automotive Yearbook 1994-95 (1994); $\mu=100, \sigma=91)$. Please refer to the text of the paper for discussions of these variables. Column (7) reports the constant and Column (8) reports the $\mathrm{R}^{2}$ for each regression. 
We add both price proxies to the right-hand side of regression 6; regressing quantity on quality, dealer cost, markup, and the markup ratio (the analogue of regression 3 in table 1). The coefficients on the markup ratio and on quality are negative and significant and the coefficient on the markup is positive and significant. If either of the two markup variables is dropped from the regression (results not reported here), then the coefficient on the remaining variable is positive and significant. This pattern would be expected if there were some aspect of quality not captured by our rating, but correlated positively with both price and quantity. "Brand-power", for example, would not necessarily show up in even a perfect measure of quality, but could easily lead to both higher prices and higher quantities. ${ }^{31}$

Overall, we find no relationship between price and our measure of quality (regressions $4 \mathrm{~A}$ and $4 \mathrm{~B}$ ). There is some evidence suggesting that our price proxies are correlated with the quantity sold, and perhaps also with an expanded concept of "quality" (regression 6). We find stronger evidence of a positive relationship between quantity and quality (regressions 5 and 6 ). Whether or not one controls for markup, quantity is significantly and positively related to our quality variable, $R A$.

The evidence for the mutual fund and automobile industries suggests that firms in these industries reap the rents from being high-quality producers primarily by enjoying higher sales rather than by charging higher prices (mutual funds) or dealer markups (automobiles). These industries illustrate well our "quantity versus price" finding for our theoretical model of the imperfect information case.

\section{Conclusion}

The models in this paper address the question: "What role does quantity play, as opposed to price, in clearing a market whose sellers differ in quality?" The model of section 2 provided a benchmark case yielding some straightforward results: the market share of the low-quality

31 Another possibility is that the omission of dealer rebates, discussed in footnote 25, could cause this result. We would expect dealer rebates to be higher for slow-selling cars; in this case, markups for slow-selling cars would be biased downward in our sample (compared to the true markups, which should include the rebate), and bias us towards finding a positive relationship between price and quantity. This would also bias us towards finding a positive univariate correlation between price and quality, so evidence for the absence of such a relationship in regressions $4 \mathrm{~A}$ and $4 \mathrm{~B}$ is strengthened. 
seller increased with its own quality, but was always lower than the market share of the highquality seller. Section 3 added convex costs of production into the model and found that the high-quality seller sometimes chooses to accept a smaller market share than its counterpart in order to set a far higher price. We also found that the ratio of the market shares was a smooth function of costs. Section 4 introduced imperfect information into the model and showed how strategic considerations could cause sellers to set identical prices, effectively softening price competition. Particularly when qualities are close, prices will be identical yet relative market shares will be very far apart. Section 5 presented empirical evidence from two industries, mutual funds and automobiles, that appear to illustrate the phenomenon of "quantity clearing the market". In both cases, proxies for quality are highly correlated with the quantity sold, and show little relation with proxies for the price or markup. 


\section{References}

Auto Test, Annual, 1994. Heathrow, FL: American Automobile Association.

Becker, G. (1991). "A Note on Restaurant Pricing and Other Examples of Social Influences on Price." Journal of Political Economy 99(5): 1109-1116.

Berry, S., J. Levinsohn and A. Pakes (1995). "Automobile Prices in Market Equilibrium." Econometrica 63(4): 841-890.

Bertrand, J. (1883). "Théorie Mathématique de la Richesse Sociale." Journal des Savants 67: 499-508.

Boom, A. (1995). "Asymmetric International Minimum Quality Standards and Vertical Differentiation." Journal of Industrial Economics 43(1): 101-119.

Bresnahan, T. and P. Reiss (1985). "Dealer and Manufacturer Margins." Rand Journal of Economics 16(2): 253-268.

Brown, K., W.V. Harlow, and L. Starks (1996). "Of Tournaments and Temptations: An Analysis of Managerial Incentives in the Mutual Fund Industry." Journal of Finance 51(1): 85-110.

Brown, S. and W. Goetzman (1995). "Performance Persistence." Journal of Finance 50(2): 679-698.

Chamberlain, E.H. (1933). The Theory of Monopolistic Competition. Cambridge, MA: Harvard University Press.

Chevalier, J. and G. Ellison (1995). "Risk Taking by Mutual Funds as a Response to Incentives." NBER Working Paper \#5234.

The Complete Car Cost Guide, Annual, 1994. San Jose: IntelliChoice, Inc.

Gabszewicz, J. Jaskold, and J.F. Thisse (1979). "Price Competition, Quality, and Income Disparities." Journal of Economic Theory 20: 340-359.

Gabszewicz, J. Jaskold, and J.F. Thisse (1980). "Entry (and Exit) in a Differentiated Industry." Journal of Economic Theory 22: 327-338.

Gabszewicz, J. Jaskold, Avner Shaked, John Sutton, and J.F. Thisse (1981). "Price Competition among Differentiated Products: A Detailed Study of Nash Equilibrium." Discussion Paper 81/37, ICERD, London School of Economics. 
Goldberg, P.K. (1995). "Product Differentiation and Oligopoly in International Markets: The Case of the U.S. Automobile Industry." Econometrica 63(4): 891-952.

Goldberg, P.K. (1996). "Dealer Price Discrimination in New Car Purchases: Evidence from the Consumer Expenditure Survey." Journal of Political Economy 104(3): 622-654.

Gompers, Paul and Josh Lerner (1996). "An Analysis of Compensation in the U.S. Venture Capital Partnership.” Manuscript, Harvard Business School.

Hackner, J. (1994). "Collusive Pricing in Markets for Vertically Differentiated Products." International Journal of Industrial Organization 12(2): 155-177.

Hendricks, D., J.Patel, and R. Zeckhauser (1993). "Hot Hands in Mutual Funds: Shortrun Persistence of Relative Performance." Journal of Finance 48(1): 93-130.

Hulbert, Mark (1996). "Price vs. Performance." The Hulbert Financial Digest 16(10): $1-2$.

Malkiel, B. (1995). "Returns to Investing in Equity Mutual Funds 1971 to 1991." Journal of Finance $\mathbf{5 0}(2)$ : 549-572.

Motta, M. (1993). "Endogenous Quality Choice - Price vs. Quantity Competition." Journal of Industrial Economics 41(2): 113-131.

Rosen, S. (1981). "The Economics of Superstars." American Economic Review 71(5): 845-858.

Rosenkranz, S. (1995). "Innovation and Cooperation under Vertical Product Differentiation." International Journal of Industrial Organization 13(1): 1-22.

Shaked, Avner and John Sutton (1982). "Relaxing Price Competition through Product Differentiation." Review of Economic Studies 49: 3-13.

Shaked, Avner and John Sutton (1983). "Natural Oligopolies." Econometrica, 51(5), September: $1469-1483$.

Sutton, John (1986). "Vertical Product Differentiation - Some Basic Themes." American Economic Review 76(2), May: 393-398.

Tirole, Jean (1988). The Theory of Industrial Organization. Cambridge, MA: MIT Press. Tufano, Peter (1989). "Financial Innovation and First-Mover Advantages." Journal of Financial Economics 25(2): 213-240.

Ward's Automotive Yearbook, Annual, 1994-95. Southfield, MI: Ward's Communications. 


\section{Appendix}

\subsection{Solution with Many Firms: Extension to Section 2}

For the case of perfect information and no costs of production, consider an industry with $M$ firms, indexed by their respective qualities $\theta_{m}$. We arbitrarily order these qualities from highest to lowest as $\theta_{1}, \theta_{2}, \ldots, \theta_{M}$, and we assume that this ordering is strict. Firms set prices sequentially in order of quality, so that the highest-quality firm sets its price first and the lowest-quality firm sets its price last. Consumers' preferences are distributed as in section 2 .

We solve the model backwards, beginning with the consumer's problem. The optimal decision rule for the consumer will be

(A) Buy from firm $m$ if

(1) $\theta_{m} v-P_{m} \geq \theta_{n} v-P_{n}$ for all $n=1, \ldots m-1$;

(2) $\theta_{m} v-P_{m}>\theta_{n} v-P_{n}$ for all $n=m+1, \ldots M$; and

(3) $I_{v}+\theta_{m} v-P_{m} \geq I_{v}$.

(B) Do not buy if $I_{v}+\theta_{m} v-P_{m}<I_{v}$ for all $m=1, \ldots, M$.

Conditions (A.1) and (A.2) ensure that a consumer who is indifferent between two products always buys the one of higher quality. This optimal decision rule will lead to a segmented market. To see why, consider two consumers indexed by their valuations of $v$ and $w$, with $w>v$. One can easily verify that if $v$ buys from firm $m$, then $w$ would never buy from any firm $n<m$. This greatly simplifies our problem, as each firm (except for firms 1 and $M$ ) will have a demand interval of

$$
Q_{m}=\left(\frac{P_{m-1}-P_{m}}{\theta_{m-1}-\theta_{m}}-\frac{P_{m}-P_{m+1}}{\theta_{m}-\theta_{m+1}}\right)
$$

It follows that each firm will have positive market share in equilibrium. As long as firm $m$ does not set a price of 0 , firm $m+1$ could also guarantee itself a positive market share and thus positive profits. Therefore, no firm would ever set a price of 0 , and the positive 
market share equilibrium is established. We are now ready to solve the game.

The profit function for firm $M$ is

$$
\pi_{M}=\left(\frac{P_{M-1}-P_{M}}{\theta_{M-1}-\theta_{M}}-\frac{P_{M}}{\theta_{M}}\right) P_{M} .
$$

Maximizing these profits with respect to $P_{M}$, we can obtain an optimal solution of

$$
P_{M}=\frac{\theta_{M} P_{M-1}}{2 \theta_{M-1}}
$$

This optimal solution can then be substituted into the profit function of firm $M-1$, which is then solved and substituted into the profit function of firms $M-2, \ldots$. The general form of the profit function for firm $m, m=2, \ldots, M-1$ is

$$
\pi_{m}=\left(\frac{P_{m-1}-P_{m}}{\theta_{m-1}-\theta_{m}}-\frac{P_{m}-P_{m+1}}{\theta_{m}-\theta_{m+1}}\right) P_{m} .
$$

The profit of firm 1 is written the same as in the duopoly case:

$$
\pi_{1}=\left(1-\frac{P_{1}-P_{2}}{\theta_{1}-\theta_{2}}\right) P_{1}
$$

where $P_{2}$ would be a function of $\theta_{1}, \theta_{2}, \ldots \theta_{M}$.

Computing the equilibrium is tedious but not difficult. The results yield similar intuition to the duopoly case. We solved a 5-firm game as an example. Figure 8 shows the equilibrium quantities of this game as a function of $\theta_{3}$, the parameter allowed to vary, drawn for the special case of $\theta_{1}=1, \theta_{2}=.8, \theta_{4}=.4$, and $\theta_{5}=.2$. The range for $\theta_{3}$ is between .4 and .8 , the levels of $\theta_{4}$ and $\theta_{2}$, respectively. When $\theta_{3}=.4$, then firm 3 will be engaged in ruinous competition with firm 4, driving both their prices and profits down to zero. In this case, firm 5 would also be driven out of business in the limit. As $\theta_{3}$ rises, firm 3 increases its market share at the expense of its two closest neighbors. Finally, as $\theta_{3}$ approaches .8 , firm 3 begins to engage in more ruinous competition with firm 2 ; in the limit, both firms' prices and profits fall to zero, and they split all the market not taken by firm 1 . At this limit, firms 4 and 5 are driven from the market. 
Figure 8 - Market Share of each Seller in a Five-Firm Oligopoly as a Function of the Third Seller's Quality

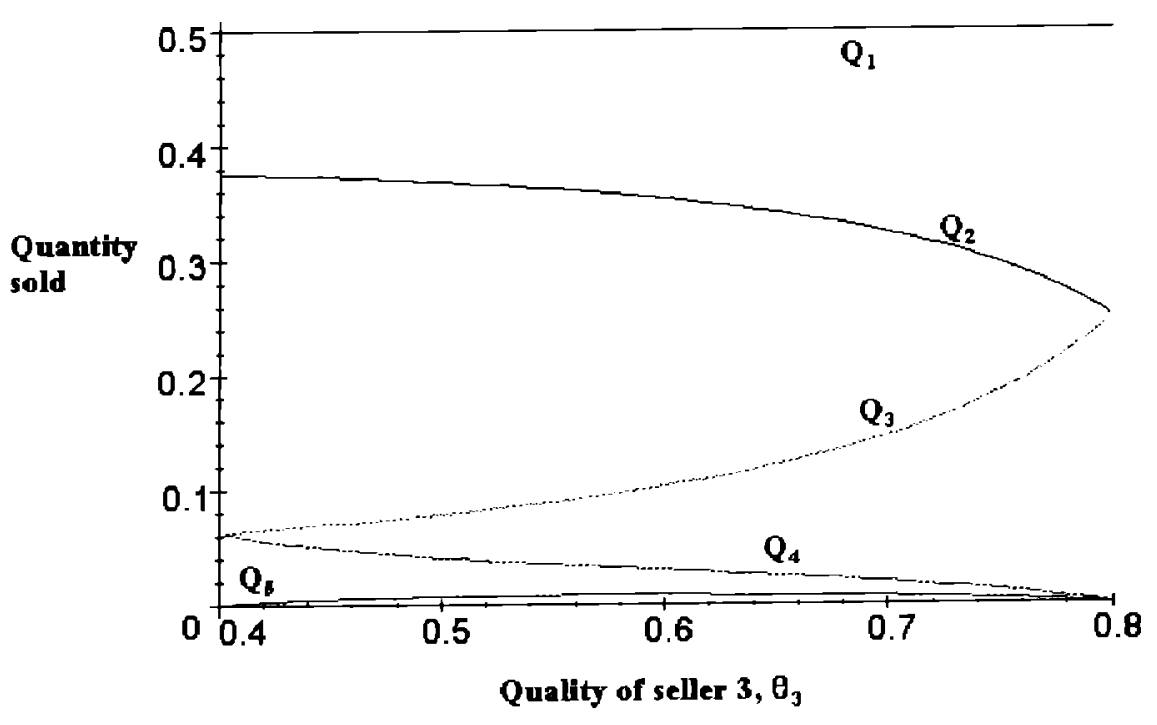

Notes: The quantity curves are plotted against $\theta_{3}$ for the case of $\theta_{1}=1, \theta_{2}=.8, \theta_{4}=.4, \theta_{5}=.2$. $\theta_{m}$ is the quality of the $\mathrm{m}^{\text {th }}$ seller. $Q_{m}$ is the quantity sold by the $\mathrm{m}^{\text {th }}$ seller.

\subsection{Solution with Convex Costs: Model from Section 3}

Solving backwards, L maximizes

$$
\pi_{L}=\left(\frac{P_{H}-P_{L}}{\theta_{H}-\theta_{L}}-\frac{P_{L}}{\theta_{L}}\right) P_{L}-\frac{c\left(\frac{P_{H}-P_{L}}{\theta_{H}-\theta_{L}}-\frac{P_{L}}{\theta_{L}}\right)^{2}}{2} .
$$

We obtain a solution of

$$
P_{L}=\left(\frac{\theta_{L}\left(\theta_{L} \theta_{H}-\theta_{L}^{2}+c \theta_{H}\right)}{\theta_{H}\left(2 \theta_{L} \theta_{H}+c \theta_{H}-2 \theta_{L}^{2}\right)}\right) P_{H}
$$

$\mathrm{H}$ maximizes

$$
\pi_{H}=\left(1-\frac{P_{H}-P_{L}}{\theta_{H}-\theta_{L}}\right) P_{H}-\frac{c\left(1-\frac{P_{H}-P_{L}}{\theta_{H}-\theta_{L}}\right)^{2}}{2},
$$


where $P_{L}$ will be replaced by its optimal value given in (38). We obtain

$$
P_{H}=\frac{\theta_{H}\left(2 \theta_{L} \theta_{H}+c \theta_{H}-2 \theta_{L}^{2}\right)\left(2 \theta_{L} \theta_{H}^{2}+c \theta_{H}^{2}+c^{2} \theta_{H}-2 \theta_{L}^{2} \theta_{H}+2 c \theta_{L} \theta_{H}-c \theta_{L}^{2}\right)}{8 c \theta_{L} \theta_{H}^{3}+8 \theta_{L}^{2} \theta_{H}^{3}+2 c^{2} \theta_{H}^{3}-12 \theta_{L}^{3} \theta_{H}^{2}+c^{3} \theta_{H}^{2}-2 c \theta_{L}^{2} \theta_{H}^{2}+4 c^{2} \theta_{L} \theta_{H}^{2}+4 \theta_{L}^{4} \theta_{H}-2 c^{2} \theta_{L}^{2} \theta_{H}-4 c \theta_{L}^{3} \theta_{H}+c \theta_{L}^{4}} .
$$

Substituting into (38) we obtain

$$
P_{L}=\frac{\theta_{L}\left(\theta_{L} \theta_{H}-\theta_{L}^{2}+c \theta_{H}\right)\left(2 \theta_{L} \theta_{H}^{2}+c \theta_{H}^{2}+c^{2} \theta_{H}-2 \theta_{L}^{2} \theta_{H}+2 c \theta_{L} \theta_{H}-c \theta_{L}^{2}\right)}{8 c \theta_{L} \theta_{H}^{3}+8 \theta_{L}^{2} \theta_{H}^{3}+2 c^{2} \theta_{H}^{3}-12 \theta_{L}^{3} \theta_{H}^{2}+c^{3} \theta_{H}^{2}-2 c \theta_{L}^{2} \theta_{H}^{2}+4 c^{2} \theta_{L} \theta_{H}^{2}+4 \theta_{L}^{4} \theta_{H}-2 c^{2} \theta_{L}^{2} \theta_{H}-4 c \theta_{L}^{3} \theta_{H}+c \theta_{L}^{4}} .
$$

Solving for $r$ yields

$$
r=\frac{Q_{L}}{Q_{H}}=\frac{\left(\frac{P_{H}-P_{L}}{\theta_{H}-\theta_{L}}-\frac{P_{L}}{\theta_{L}}\right)}{\left(1-\frac{P_{H}-P_{L}}{\theta_{H}-\theta_{L}}\right)}=\frac{\theta_{L}\left(2 \theta_{L} \theta_{H}^{2}+c \theta_{H}^{2}+c^{2} \theta_{H}-2 \theta_{L}^{2} \theta_{H}+2 c \theta_{L} \theta_{H}-c \theta_{L}^{2}\right)}{4 c \theta_{L} \theta_{H}^{2}+4 \theta_{L}^{2} \theta_{H}^{2}+c^{2} \theta_{H}^{2}-3 c \theta_{L}^{2} \theta_{H}-6 \theta_{L}^{3} \theta_{H}+2 \theta_{L}^{4}}
$$

Result $2^{\prime}$ of section 3 is that $\frac{\partial r}{\partial \theta_{L}}>0$ and $\frac{\partial r}{\partial \theta_{H}}<0$. We can confirm these results by directly evaluating the derivatives:

$$
\frac{\partial r}{\partial \theta_{L}}=\frac{4 \theta_{L}^{4} \theta_{H}^{3}+4 \theta_{L}^{6} \theta_{H}-8 \theta_{L}^{5} \theta_{H}^{2}+c\left(8 \theta_{L}^{4} \theta_{H}^{2}-4 \theta_{L}^{3} \theta_{H}^{3}+2 \theta_{L}^{6}-8 \theta_{L}^{5} \theta_{H}+4 \theta_{L}^{2} \theta_{H}^{4}\right)+c^{2}\left(4 \theta_{L} \theta_{H}^{4}+\theta_{L}^{2} \theta_{H}^{3}-3 \theta_{L}^{4} \theta_{H}+4 \theta_{L}^{3} \theta_{H}^{2}\right)+c^{3}\left(\theta_{H}^{4}+4 \theta_{L} \theta_{H}^{3}\right)+c^{4} \theta_{H}^{3}}{\left(2 \theta_{L}^{4}-6 \theta_{L}^{3} \theta_{H}-3 c \theta_{L}^{2} \theta_{H}+4 \theta_{L}^{2} \theta_{H}^{2}+4 c \theta_{L} \theta_{H}^{2}+c^{2} \theta_{H}^{2}\right)^{2}} ;
$$

since we know that $\theta_{H}>\theta_{L}$, we can eliminate many of these terms and write

$$
\frac{\partial r}{\partial \theta_{2}}>\frac{2 c \theta_{L}^{6}+4 \theta_{L} \theta_{H}^{4} c^{2}+c^{2} \theta_{L}^{2} \theta_{H}^{3}+c^{3} \theta_{H}^{4}+4 c^{3} \theta_{L} \theta_{H}^{3}+c^{4} \theta_{H}^{3}}{\left(2 \theta_{L}^{4}-6 \theta_{L}^{3} \theta_{H}-3 c \theta_{L}^{2} \theta_{H}+4 \theta_{L}^{2} \theta_{H}^{2}+4 c \theta_{L} \theta_{H}^{2}+c^{2} \theta_{H}^{2}\right)^{2}}>0 .
$$

Similarly, we evaluate

$$
\frac{\partial r}{\partial \theta_{H}}=\frac{-\theta_{L}\left(-8 \theta_{L}^{5} \theta_{H}+4 \theta_{L}^{4} \theta_{H}^{2}+4 \theta_{L}^{6}+2 c \theta_{L}^{5}-12 c \theta_{L}^{4} \theta_{H}+12 c \theta_{L}^{3} \theta_{H}^{2}+13 c^{2} \theta_{L}^{2} \theta_{H}^{2}-8 c^{2} \theta_{L}^{3} \theta_{H}+c^{2} \theta_{L}^{4}+6 c^{3} \theta_{L} \theta_{H}^{2}-2 c^{3} \theta_{L}^{2} \theta_{H}+c^{4} \theta_{H}^{2}\right)}{\left(2 \theta_{L}^{4}-6 \theta_{L}^{3} \theta_{H}-3 c \theta_{L}^{2} \theta_{H}+4 \theta_{L}^{2} \theta_{H}^{2}+4 c \theta_{L} \theta_{H}^{2}+c^{2} \theta_{H}^{2}\right)^{2}} ;
$$

since $\theta_{H}>\theta_{L}$ we can eliminate many terms for an inequality result, namely

$$
\frac{\partial r}{\partial \theta_{H}}<\frac{-\theta_{L}\left(2 c \theta_{L}^{5}+c^{2} \theta_{L}^{4}+c^{4} \theta_{H}^{2}\right)}{\left(2 \theta_{L}^{4}-6 \theta_{L}^{3} \theta_{H}-3 c \theta_{L}^{2} \theta_{H}+4 \theta_{L}^{2} \theta_{H}^{2}+4 c \theta_{L} \theta_{H}^{2}+c^{2} \theta_{H}^{2}\right)^{2}}<0 .
$$

Result $2^{\prime}$ is established.

\subsection{Solution with Imperfect Information: Proof of Proposition 1 from Section 4}

To prove this proposition, as well as to draw the figures of section 4 , we first need to solve 
for five expressions:

(1) $\pi_{H}^{s}$ - Separating profits for $\mathrm{H}$ if we ignore the constraint in (27).

(2) $\pi_{H}^{\bar{s}}$ - Separating profits for $\mathrm{H}$ when the constraint in (27) binds exactly.

(3) $\lambda^{s}$ - The minimum level of $\lambda$ for which the constraint in (27) holds.

(4) $\pi_{H}^{p}$ - Pooling profits for $\mathrm{H}$ if we ignore the constraint in (28).

(5) $\pi_{H}^{\bar{p}}$ - Pooling profits for $\mathrm{H}$ when the constraint in (28) binds exactly.

After solving for these five expressions, we are able to compare H's pooling and separating profits for all levels of $\lambda$ and $\alpha$, and show that when the conditions of the proposition are met, pooling profits will always be higher.

\section{Separating Equilibrium}

The problem is to maximize

$$
\begin{gathered}
\pi_{H}^{s}=N\left(1-\frac{P_{H}-\frac{\alpha P_{H}}{2}}{\beta}\right) P_{H}, \\
\text { subject to } P_{H} \geq \frac{2 \lambda \beta(1+\alpha)}{\alpha(1+\alpha)+4 \lambda(1-\alpha)} .
\end{gathered}
$$

When the constraint does not bind, the solution is

$$
P_{H}=\frac{\beta}{2-\alpha}
$$

yielding profits of

$$
\pi_{H}^{s}=\frac{\beta}{2(2-\alpha)} .
$$

The relevant second-order conditions hold here, so whenever the constraint binds, it will bind exactly and profits will be

$$
\pi_{H}^{\bar{s}}=\frac{2 \beta \lambda(\alpha+1)\left(\alpha^{2}+\alpha+2 \lambda-5 \lambda \alpha+\lambda \alpha^{2}\right)}{\left(\alpha^{2}+\alpha+4 \lambda-4 \lambda \alpha\right)^{2}},
$$

where $\pi_{H}^{\bar{s}}$ refers to profits for the high-quality producer in the separating equilibrium when the constraint binds. The constraint will bind when 


$$
\frac{\beta}{2-\alpha}=\frac{2 \lambda \beta(1+\alpha)}{\alpha(1+\alpha)+4 \lambda(1-\alpha)}
$$

This occurs at

$$
\lambda^{s}=\frac{1+\alpha}{6-2 \alpha}
$$

\section{Pooling Equilibrium}

The problem is to maximize

$$
\begin{gathered}
\pi_{H}^{p}=(1-\lambda)\left(1-\frac{P_{H}}{\theta_{H}}\right) P_{H}+\frac{\lambda}{2}\left(1-\frac{2 P_{H}}{\theta_{H}+\theta_{L}}\right) P_{H} \\
\text { subject to } P_{H} \leq \frac{2 \lambda \beta(1+\alpha)}{\alpha(1+\alpha)+4 \lambda(1-\alpha)} .
\end{gathered}
$$

When the constraint does not bind, the solution is

$$
P_{H}=\frac{(\alpha+1)(2-\lambda) \beta}{4\left(1-\alpha^{2}-\lambda \alpha+\lambda \alpha^{2}\right)}
$$

and pooling profits will be

$$
\pi_{H}^{p}=\frac{(2-\lambda)^{2}(\alpha+1) \beta}{16\left(1-\alpha^{2}-\lambda \alpha+\lambda \alpha^{2}\right)} .
$$

When the constraint does bind, profits will be

$$
\pi_{H}^{\bar{p}}=\frac{\lambda \beta(\alpha+1)\left(2 \alpha^{2}+2 \alpha+4 \lambda-9 \lambda \alpha+3 \lambda \alpha^{2}-4 \lambda^{2}+8 \lambda^{2} \alpha-4 \lambda^{2} \alpha^{2}\right)}{\left(\alpha^{2}+\alpha+4 \lambda-4 \lambda \alpha\right)^{2}}
$$

\section{Comparing Separating and Pooling Profits}

We need to show that pooling profits are always larger than separating profits whenever we have both $\alpha \geq .55$ and $\lambda>\frac{1+\alpha}{6-2 \alpha}$. Since $\lambda=\frac{1+\alpha}{6-2 \alpha}$ is exactly the point at which separating profits become constrained, and since $\pi_{H}^{p} \geq \pi_{H}^{\bar{p}}$, it will suffice to show that $\pi_{H}^{\bar{p}}>\pi_{H}^{\bar{s}}$ for the set $\alpha \geq .55 \cap \lambda>\frac{1+\alpha}{6-2 \alpha}$. From (46) and (52), we have $\pi_{H}^{\bar{p}}>\pi_{H}^{\bar{s}}$ if and only if

$$
\frac{\lambda \beta(\alpha+1)\left(2 \alpha^{2}+2 \alpha+4 \lambda-9 \lambda \alpha+3 \lambda \alpha^{2}-4 \lambda^{2}+8 \lambda^{2} \alpha-4 \lambda^{2} \alpha^{2}\right)}{\left(\alpha^{2}+\alpha+4 \lambda-4 \lambda \alpha\right)^{2}}>\frac{2 \lambda \beta(\alpha+1)\left(\alpha^{2}+\alpha+2 \lambda-5 \lambda \alpha+\lambda \alpha^{2}\right)}{\left(\alpha^{2}+\alpha+4 \lambda-4 \lambda \alpha\right)^{2}} .
$$

This condition reduces to 


$$
\lambda<\frac{\alpha+\alpha^{2}}{4-8 \alpha+4 \alpha^{2}} .
$$

This will hold for $\lambda \leq 1$ (and, thus, for all possible $\lambda$ ) when

$$
\frac{\alpha+\alpha^{2}}{4-8 \alpha+4 \alpha^{2}}>1 \rightarrow \alpha>.54327
$$

Thus, whenever $\alpha>.54327$, we will have $\pi_{H}^{\bar{p}}>\pi_{H}^{\bar{s}} \forall \lambda$, and, a fortiori $\forall \lambda>\frac{1+\alpha}{6-2 \alpha}$. (Thus, our condition in the proof that $\alpha \geq .55$ is slightly stronger than we need.)

Section 4 contains several figures that can help give some intuition for this result.

We can also use this result to verify Result $2^{\prime \prime}$. At $\alpha=.5, \lambda=1$, we have the constraint bind for separating profits, and these constrained separating profits are larger than pooling profits: $\pi_{H}^{\bar{s}}=\pi_{H}^{s}>\pi_{H}^{p}$. Thus, we have a separating equilibrium at this point, with prices (calculated from (23) and (26)) of $P_{H}=.54545$ and $P_{L}=.13636$. Solving for the quantities sold by each firm yields $r=3$. 